\title{
Simulation of Monsoon Precipitation over South-Asia Using RegCM3
}

\author{
Abdul Basit, ${ }^{1}$ S. Shoaib Raza, ${ }^{2}$ N. Irfan, ${ }^{2}$ and R. Avila ${ }^{3}$ \\ ${ }^{1}$ National Engineering and Scientific Commission (NESCOM), Islamabad 44000, Pakistan \\ ${ }^{2}$ Faculty of Engineering, Pakistan Institute of Engineering and Applied Sciences (PIEAS), Islamabad 44000, Pakistan \\ ${ }^{3}$ Departamento de Termofluidos, Facultad de Ingeniera, Universidad Nacional Autónoma de México (UNAM), \\ 0451 México, DF, Mexico \\ Correspondence should be addressed to Abdul Basit, abjilani@gmail.com
}

Received 16 August 2011; Accepted 12 September 2011

Academic Editor: L.-T. Hsieh

Copyright ( $) 2012$ Abdul Basit et al. This is an open access article distributed under the Creative Commons Attribution License, which permits unrestricted use, distribution, and reproduction in any medium, provided the original work is properly cited.

The objective of this study is to explore the capability of the Regional Climate Model (RegCM3), to predict the extreme weather events in south-Asian region with particular reference to precipitation during monsoon season (July, August and September) over northern mountainous and southern plain regions of Pakistan. Different cumulus parameterization schemes in RegCM3 for prediction of convective precipitation are tested for monsoon period during the years 1998 and 2001. The model results are compared with the Climate Research Unit (CRU) observational data and the surface synoptic data of the Pakistan Meteorological Department (PMD). The year 1998 was a dry year and proved to be the beginning of a severe drought lasted up to the year 2000. While in year 2001 the precipitation over some parts of the country exceeded the normal, especially the northern parts of the country observed exceptionally high rainfall rate. The results indicate that some convective parameterization schemes of RegCM3 well captured the summer monsoon precipitation over Pakistan. However, the schemes need to be selected carefully depending upon the region of interest. It was found that the Grell scheme with both closures: Arakawa-Schubert (AS) and Fritsch-Chappell (FC) satisfactorily captured the monsoon phenomenon in Pakistan specially for the northern mountainous regions.

\section{Introduction}

Due to their coarse resolution General Circulation Models (GCMs) often perform poorly in simulating regional processes, especially in regions with local fine-scale forcing topography $[1,2]$. On the other hand, modeling studies with regional climate models also indicated that some cumulus parameterization schemes do not perform well in some specific regions of the world, for example, Asian monsoon regions $[3,4]$. Scale interactions are extremely complex in the Asian monsoon regions [5], which are further complicated due to the effects of Tibetan plateau, oceancontinent contrast and sea-air interactions. These specific features require special consideration in designing regional climate models to be used in this particular region.

The impacts of climate change on food and water resources of a country depend on both regional and global scale changes and the interactions between them. It is therefore imperative to understand how global climate change is manifested in global and regional scale climate models. Using GCM output to drive limited-area atmospheric simulations on regional scales has been reported to be a promising approach for simulating regional climates $[6,7]$. According to this approach a limited-area model with ability to resolve complex topography, land-sea contrast, land use and complex physical processes generates realistically high-resolution (spatially and temporally) information coherent with the driving large-scale circulation (output of GCM).

A critical weakness that needs improvement in both global and regional climate models is the treatment of clouds [7]. Although the detailed explicit cloud microphysics parameterization for grid resolved moist processes is considered in some of the regional climate models but the complex interaction between subgrid cumulus convection and grid scale moist processes is generally crudely treated. 
Some studies have indicated the improvements in estimation of cloud water content and specific humidity by using cloud microphysics information $[8,9]$, but in most of the climate model applications, the cloud amount is treated in a quite simple way and is usually estimated by the relative humidity [10-13]. Although some previous studies [14] have shown the capability of regional climate models in reproducing intra-annual variability when initialized by good-quality-driving fields of temperature, pressure, velocity and so forth but still more analysis is needed to improve model performance in simulating climate variability at short timescales (days to weeks). The fine resolution of regional climate models brings improvement in broad spectrum weather events which results in better daily and monthly precipitation intensity and distribution.

The paper discusses the capabilities of RegCM3 to simulate the precipitation intensity and its patterns during summer monsoon season in the Indian subcontinent with particular emphasis over Pakistan. The summer monsoon systems originate from the Bay of Bengal, Indian Ocean, and sometimes get accentuated by the juxtaposition of passing westerly disturbances and the Arabian Sea component. The model results are compared with observed data (from Pakistan Meteorological Department and Climate Research Unit). The purpose is to identify some suitable cumulus parameterization schemes for predicting the summer monsoon precipitation (July to September) for South-Asia in general and Pakistan in particular.

\section{Description of the Model (RegCM3)}

The regional scale model used in this work is the Regional Climate Model, version 3 (RegCM3) developed at Abdus Salam International Center for Theoretical Physics (ASICTP), Italy. RegCM was originally developed at the National Center for Atmospheric Research (NCAR) based upon the NCAR-Pennsylvania State University (PSU) Mesoscale Model (MM4) in the late 1980s [15-17]. The dynamical component of the model is a compressible, finite difference scheme with hydrostatic balance and vertical $\sigma$ (sigma) coordinates. Later, an explicit-time split integration scheme was added along with an algorithm for reducing horizontal diffusion in the presence of steep topographical gradients $[10,11]$. The first generation RegCM included the Biosphere-Atmosphere Transfer Scheme (BATS) [18] for surface process representation, a radiative transfer scheme, a medium resolution local planetary boundary layer scheme, the convection scheme of Anthes [19] and the explicit moisture scheme of Hsie et al. [20].

Present version of RegCM (RegCM3) includes a nonlocal boundary layer scheme [21], the mass flux cumulus schemes of Grell [22] with Arakawa and Schubert [23] and Fritsch and Chappell [24] closures, a modified Kuo scheme [19], BettsMiller scheme $[25,26]$ and a new parameterization of Zeng et al. [27] for ocean surface fluxes. Subgrid Explicit Moisture Scheme (SUBMEX) is used to handle nonconvective clouds and precipitation by the regional climate model [28]. The RegCM3 can be run with the input data of US Geological

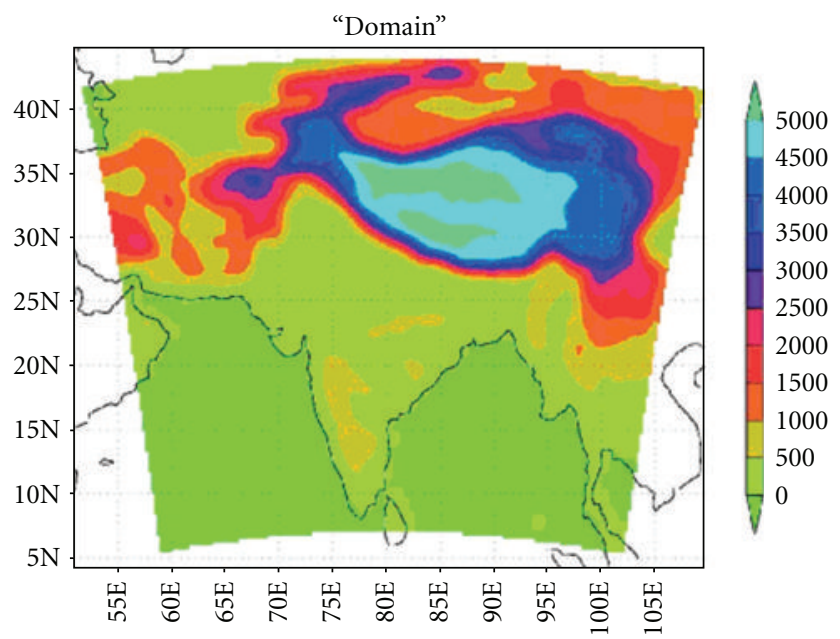

FIGURE 1: Topographic map of the region with 10-minute resolution.

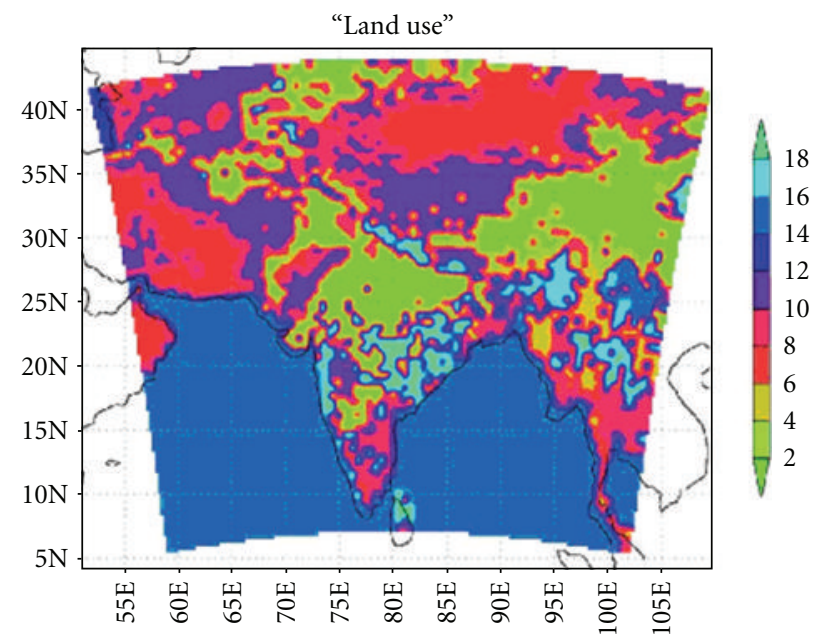

FIGURE 2: Land use map of the region with 10-minute resolution.

Survey (USGS) for the global land cover characterization and elevation datasets to create the terrain files, in addition to the NCEP and ECMWF global reanalysis datasets for use as initial and boundary conditions. As in most of other grid point regional climate models, a one-way nesting is used to update the model time integration in a buffer zone near the lateral boundaries within which the model prognostic variables are nudged to the reanalysis data or the GCM results with an exponential nudging coefficient proposed by Giorgi et al. [11] and later modified by Liang et al. [29].

Terrestrial variables (elevation, land use, and sea surface temperature) and 3D isobaric variables are horizontally interpolated from a latitude-longitude mesh to a highresolution domain on a rotated (or normal) Mercator (suitable for low latitudes), Lambert conformal or polar stereographic projection. Vertical interpolation from pressure levels to the $\sigma$-coordinate system is also performed. The $\sigma$ surfaces near the ground closely follow the terrain and at higher levels tend to become flat. The horizontal grid 


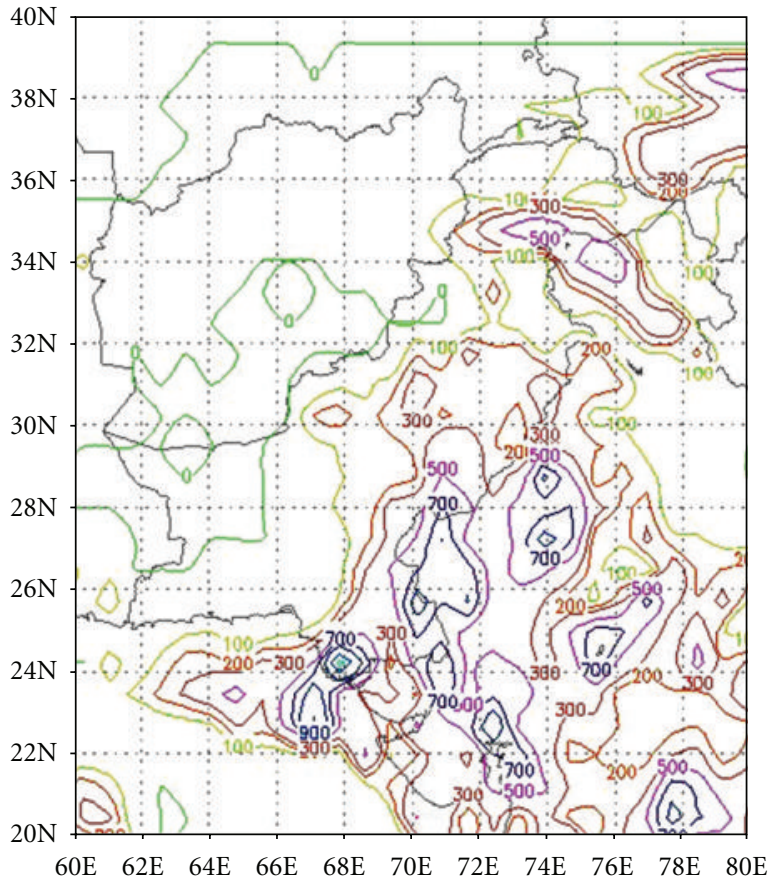

(a)

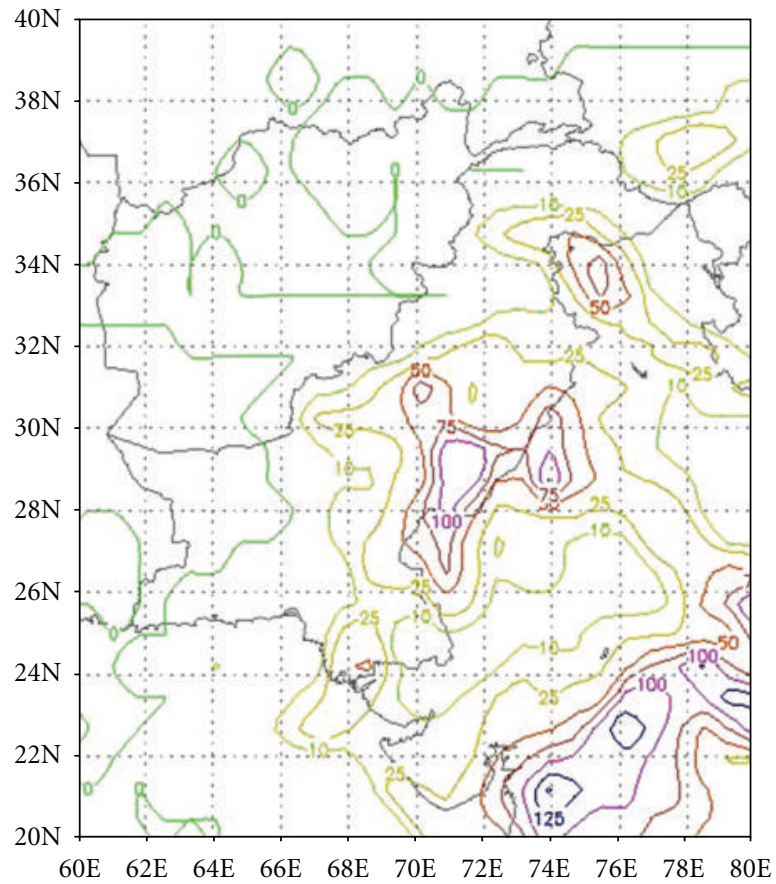

(c)

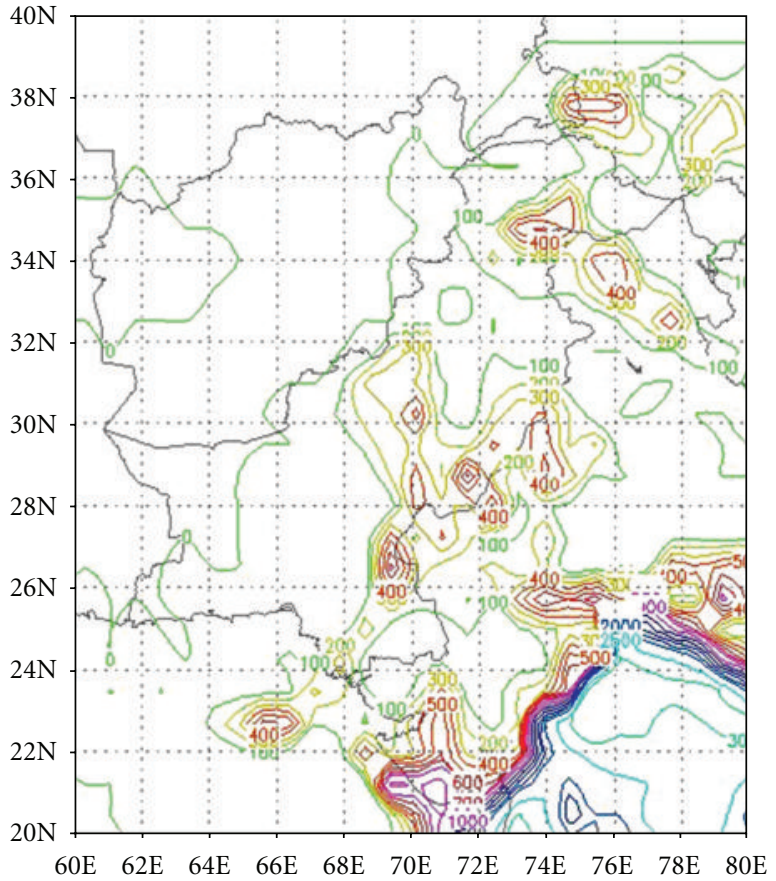

(b)

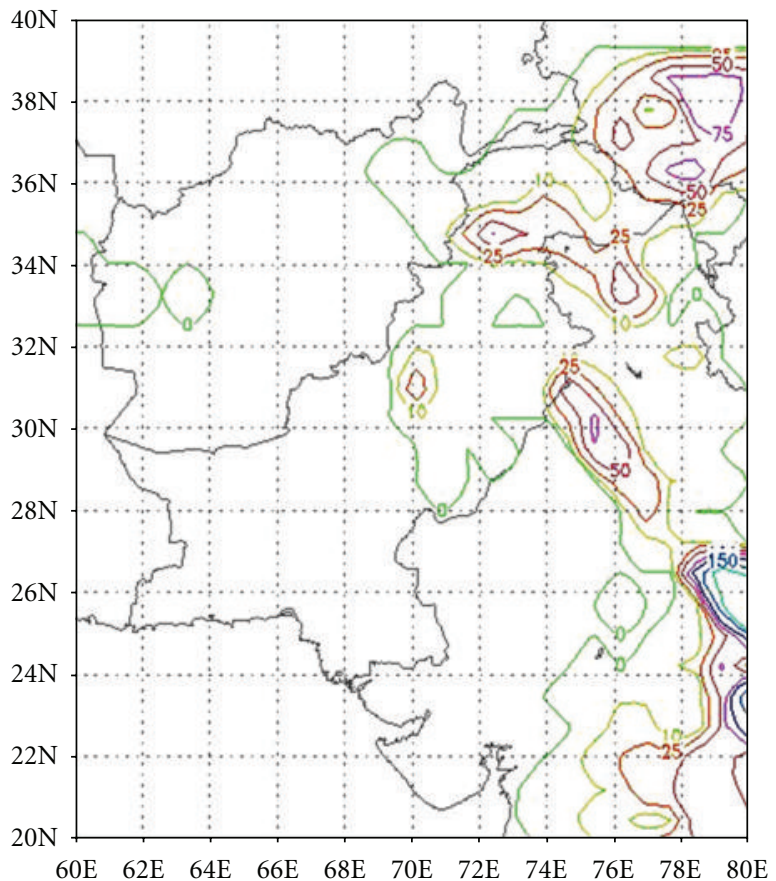

(d)

FIGURE 3: Model simulated isohyetal maps for the month of July 1998 with four parameterization schemes: Grell-AS, Grell-FC, modified Kuo and Betts-Miller schemes.

has an Arakawa-Lamb B-staggering of the velocity variables with respect to the scalar variables (T, q, P, etc.). Prognostic variables in the cloud microphysics scheme include mixing ratios of water vapor, cloud water, rain water, cloud ice and snow. Cloud water is assumed to move with air while cloud ice precipitates with the terminal velocity given by
Heymsfield and Donner [30]. Condensation/evaporation of cloud water takes place instantaneously when the air is supersaturated/subsaturated.

The subgrid-scale vertical mixing is accomplished by the so-called E- $\varepsilon$ turbulence closure scheme in which both turbulent kinetic energy and its dissipation rate are 


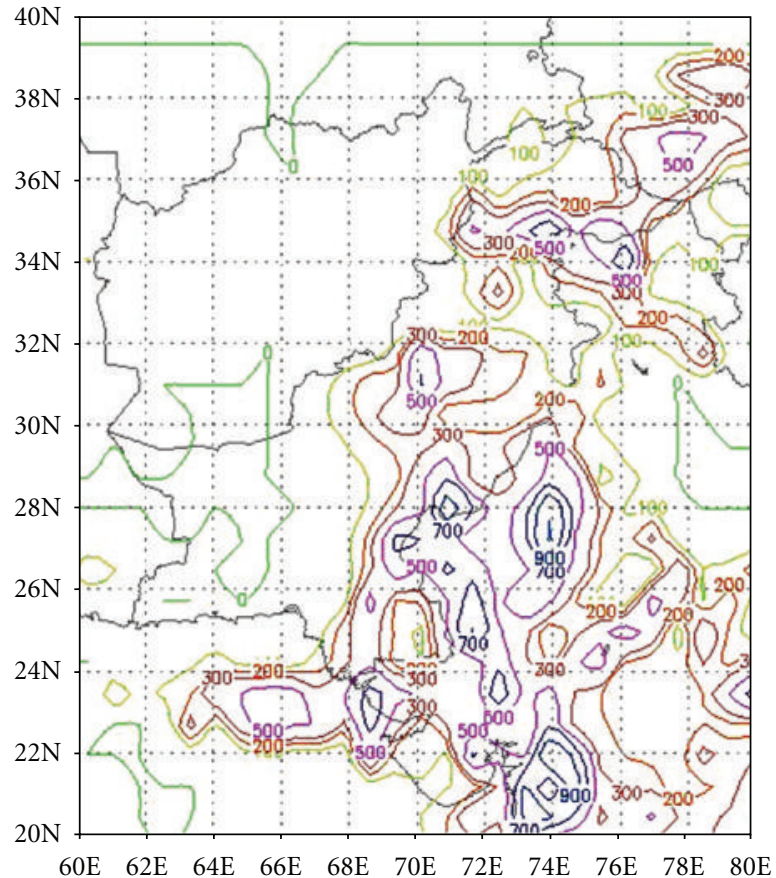

(a)

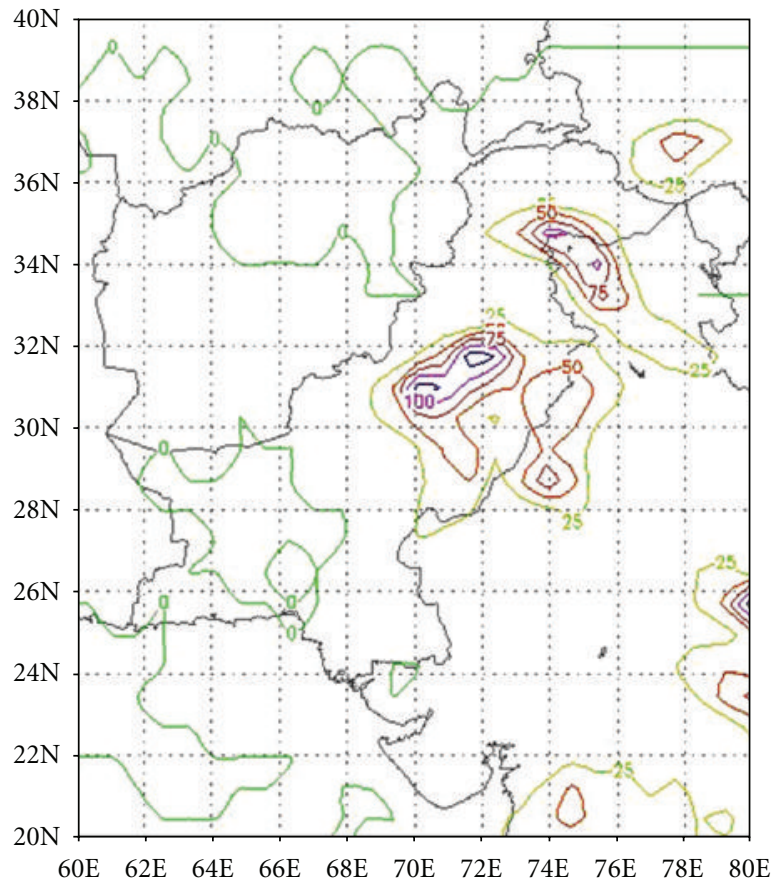

(c)

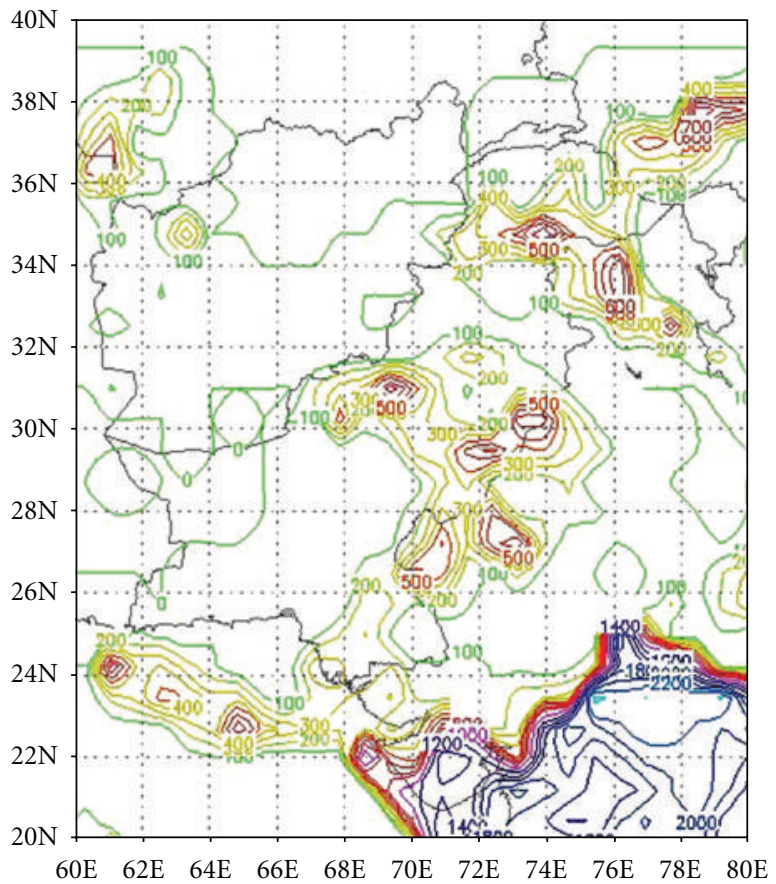

(b)

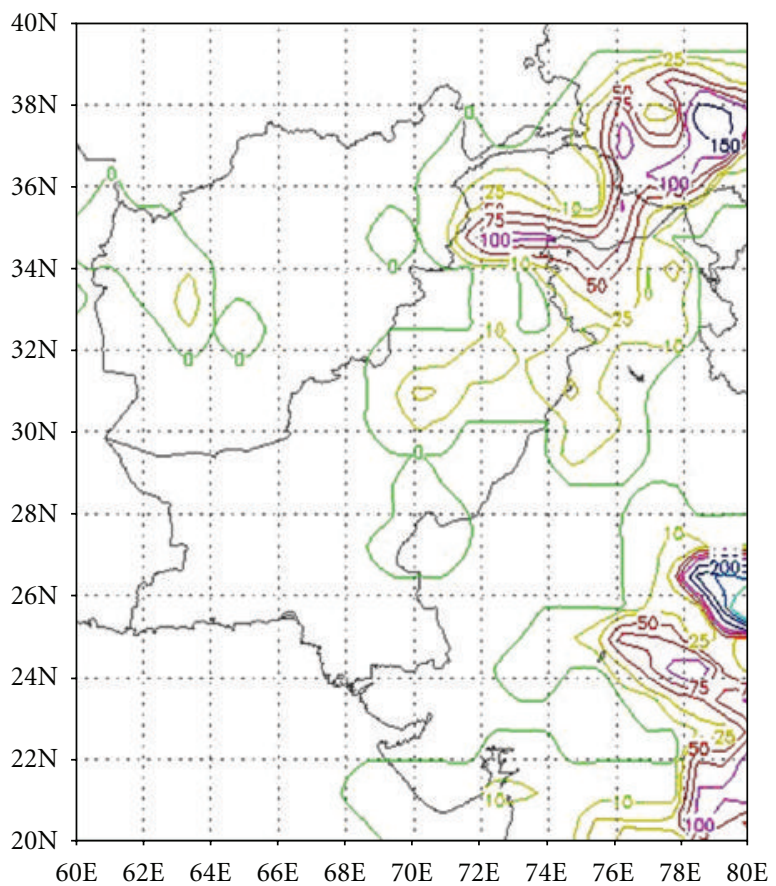

(d)

FIGURE 4: Model simulated isohyetal maps for the month of August 1998 with four parameterization schemes: Grell-AS, Grell-FC, modified Kuo and Betts-Miller schemes.

prognostic variables [31]. Turbulent fluxes at the ocean surface are calculated using the modified Monin Obukhov scheme based on the Tropical Ocean Global Atmosphere Coupled Ocean-Atmosphere Response Experiment (TOGA COARE) algorithm [32]. Turbulent fluxes over the land surface are calculated based on the bulk aerodynamic method used in the land surface scheme. Dissipative heating due to molecular friction in the planetary boundary layer is considered to conserve the internal energy of the atmosphere.

To include the land surface processes, the Biosphere Atmosphere Transfer Scheme (BATS) developed by Dickinson 


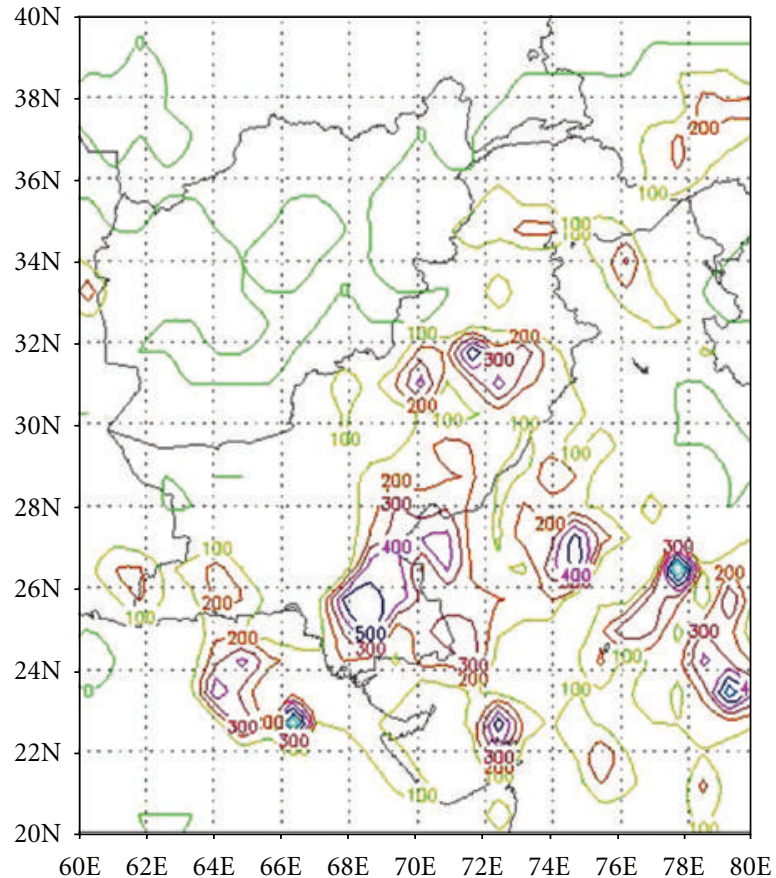

(a)

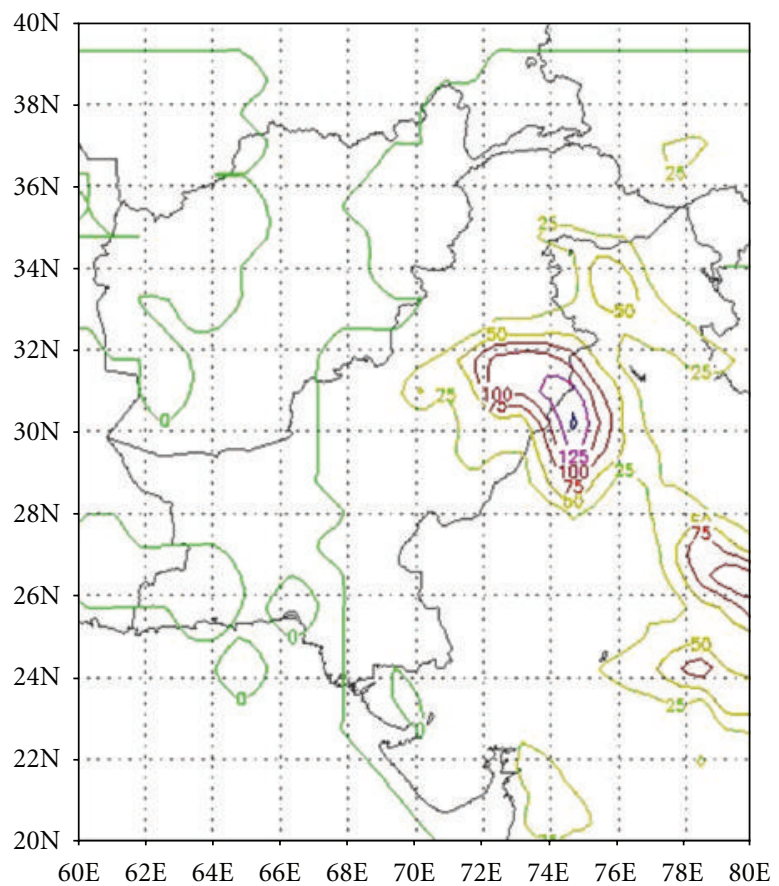

(c)

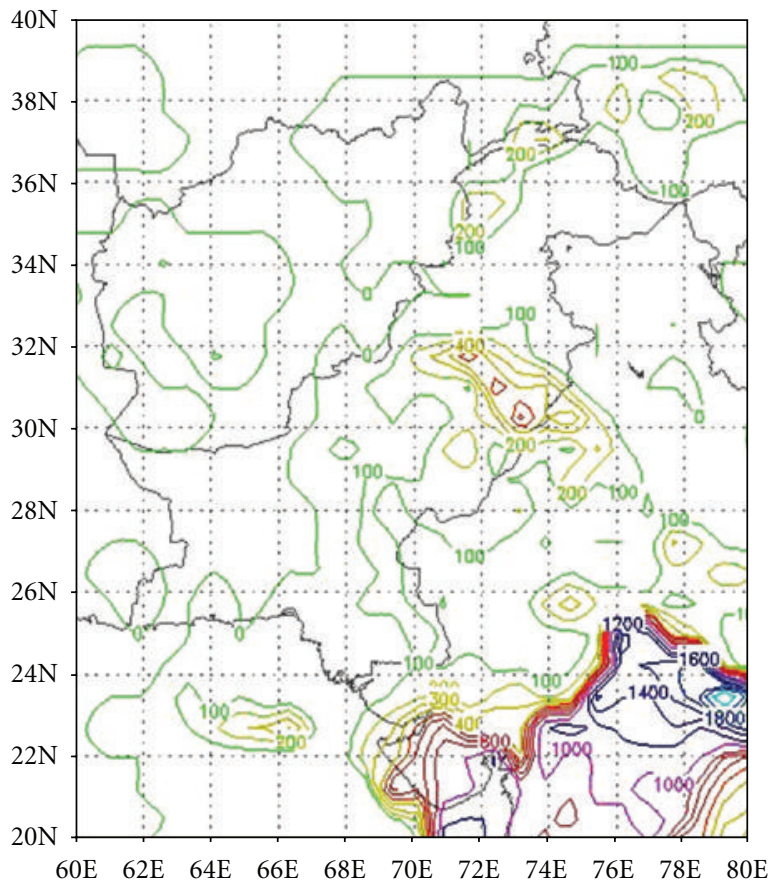

(b)

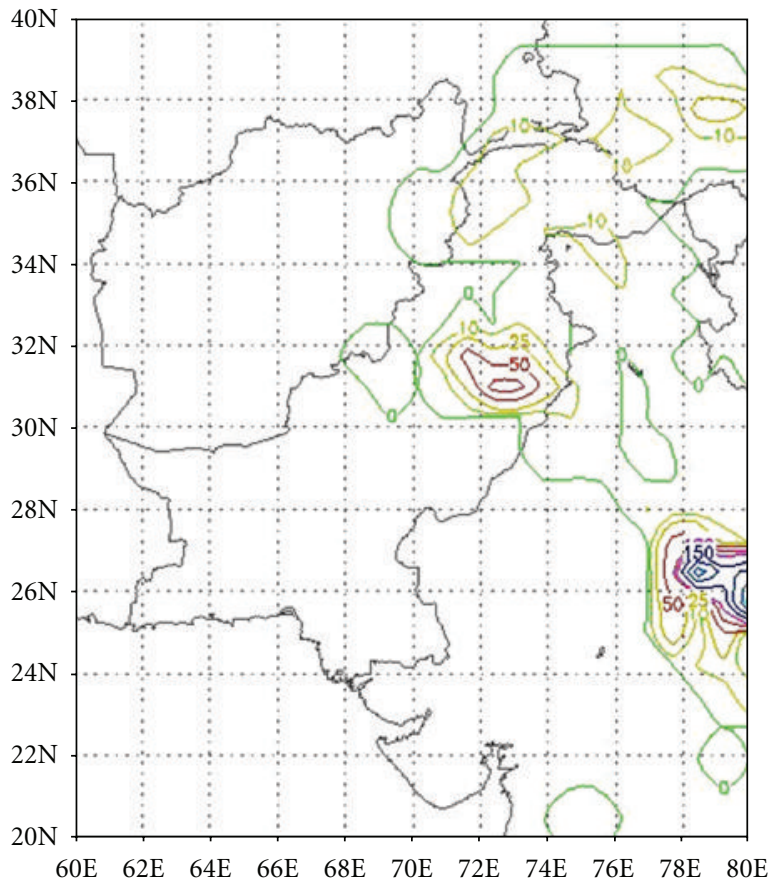

(d)

FIGURE 5: Model simulated isohyetal maps for the month of September 1998 with four parameterization schemes: Grell-AS, Grell-FC, modified Kuo and Betts-Miller schemes.

et al. [18] is coupled with the atmospheric model by a semi-implicit coupling algorithm [33]. BATS incorporates one canopy and three soil layers and it requires land cover/vegetation (20 types), soil texture (12 types) and soil color (8 types) maps for spatial applications as in a GCM. In our application, these datasets were obtained from the second version of USGS $1-\mathrm{km}$ resolution land cover classification dataset and the US Department of Agriculture global $10-\mathrm{km}$ resolution soil data. Soil water content is initialized using a method described by Giorgi and Bates [17] such that the initial values depend on the vegetation and soil type defined for each grid cell. 


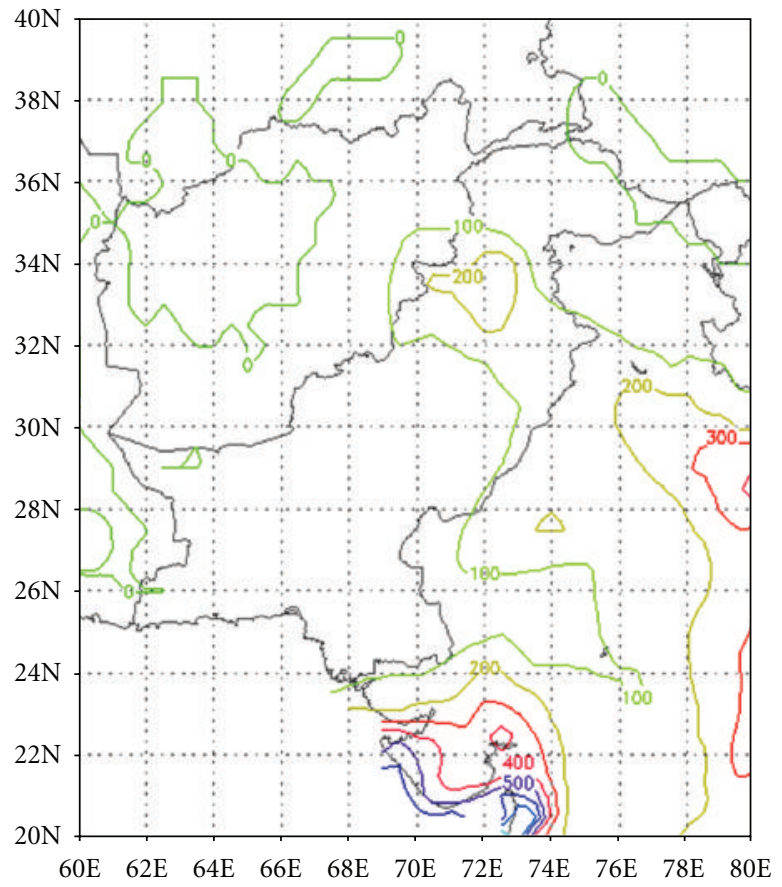

(a)

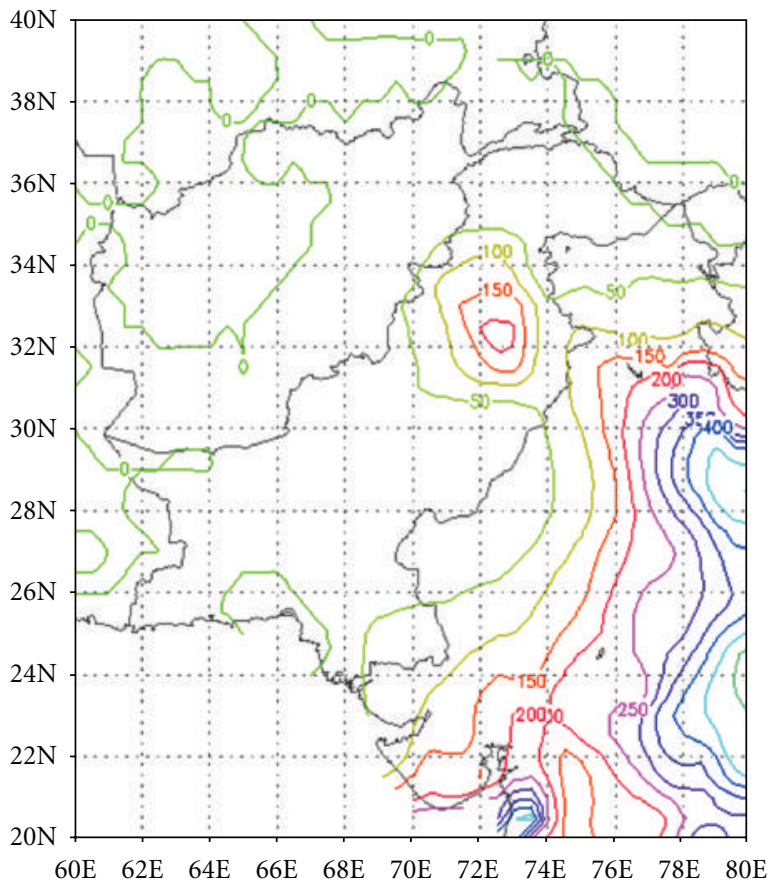

(b)

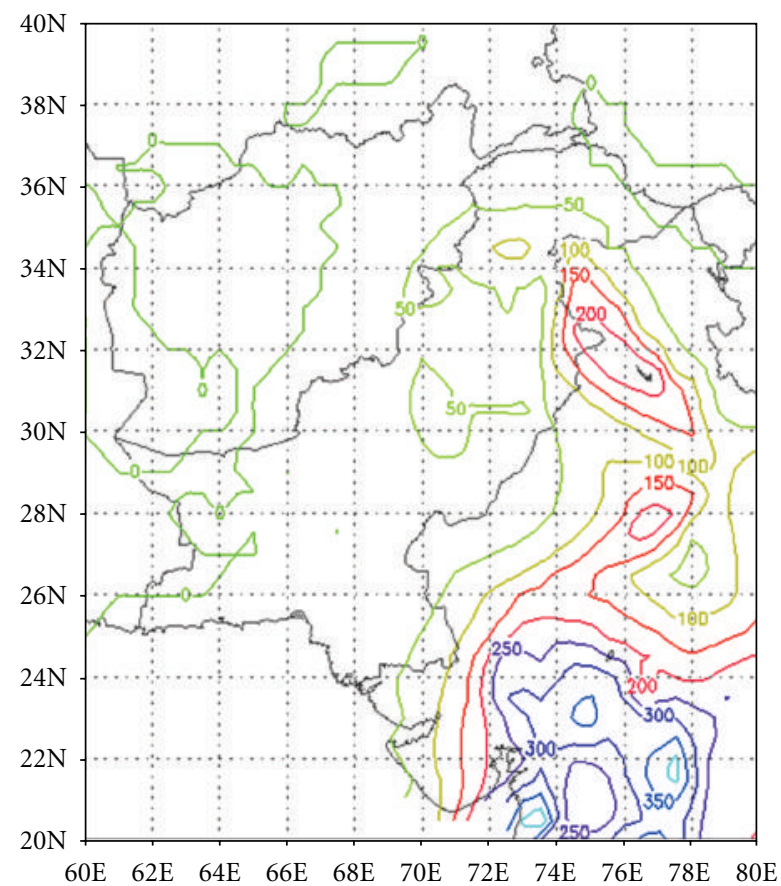

(c)

Figure 6: Isohyetal maps based on CRU data for the months of July, August and September 1998.

\section{Prediction of Summer Monsoon Precipitation over South-Asia Region}

Model capabilities have been accessed to predict the summer monsoon precipitation over south-Asia Region with special focus on the Pakistan area. The outstanding characteristic of Pakistan's climate is dryness. More than three-quarters of the country receive an annual rainfall of less than
$250 \mathrm{~mm}$ and the area receiving more than $500 \mathrm{~mm}$ (from Rawalpindi to Sialkot, north of Lahore) rainfall is about $7 \%$ and mostly lies on mountain slopes. Over the Indus plains more than half the rainfall comes in the three months of summer monsoon: July, August and September. During winter (December-January-February) season, most of the rainfall over the north and west fringes of mountains comes from passing depressions originating from 


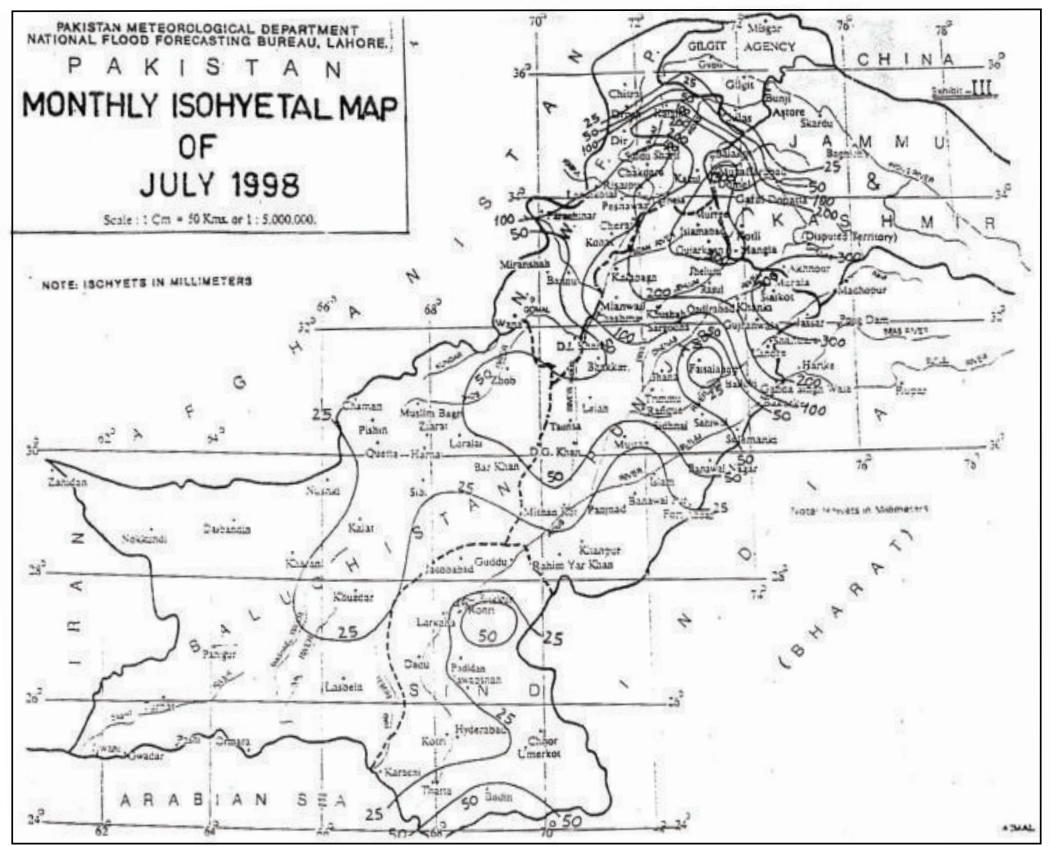

(a)

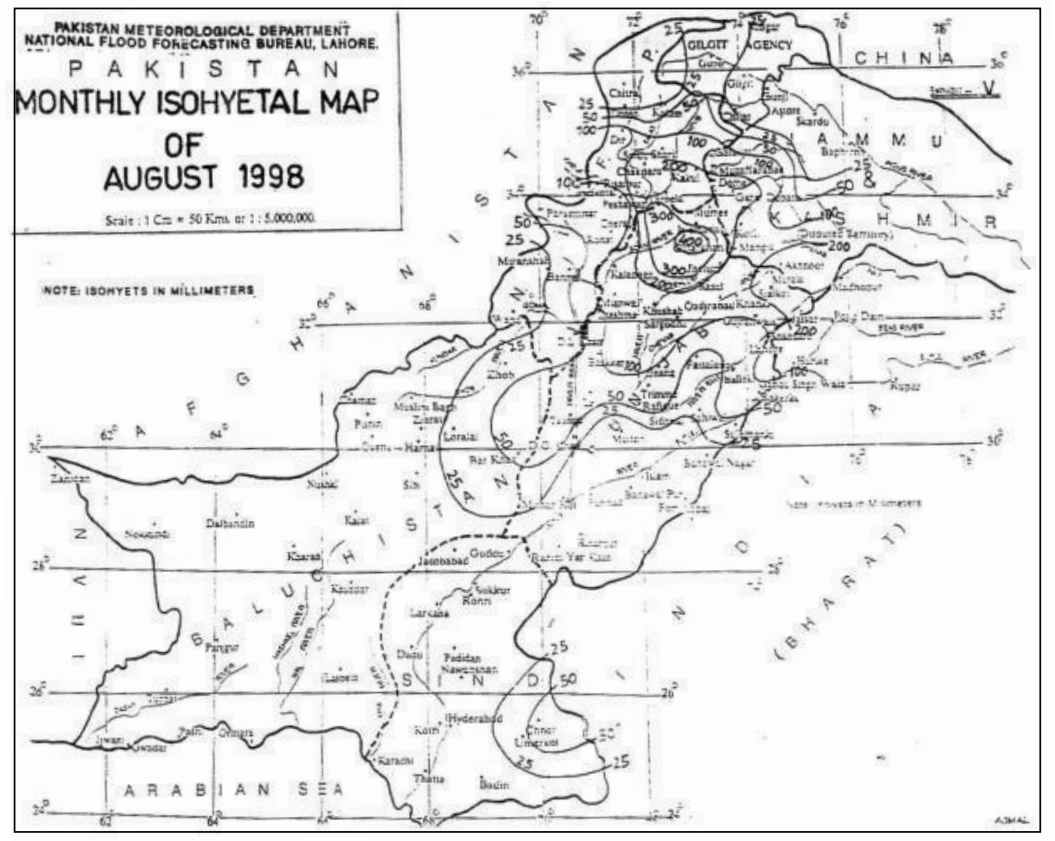

(b)

Figure 7: Isohyetal maps for observed PMD data for the months of July and August, 1998.

the Mediterranean. Except for some western regions that receive high precipitation during winter, the rest of the country receives high precipitation during summer monsoon season only. The high rainfall during summer months is attributed to the flow of southwesterly winds from the Arabian Sea and southeasterly strong currents from the Bay of Bengal. Occasionally, an inflow of moist air from the Arabian sea and simultaneously from Bay of Bengal juxtaposed with the passing westerly disturbances bringing heavy rainfall over the upper catchments of the Indus Basin System.

Different cumulus parameterization schemes in RegCM3 for prediction of convective precipitation were tested for monsoon period during the years 1998 and 2001. It would 


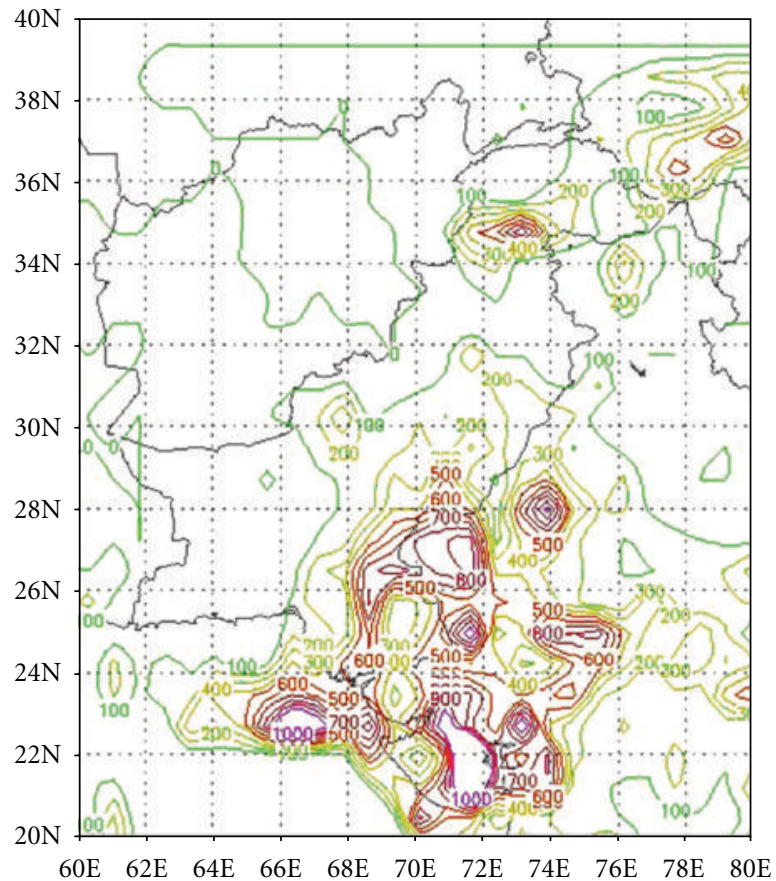

(a)

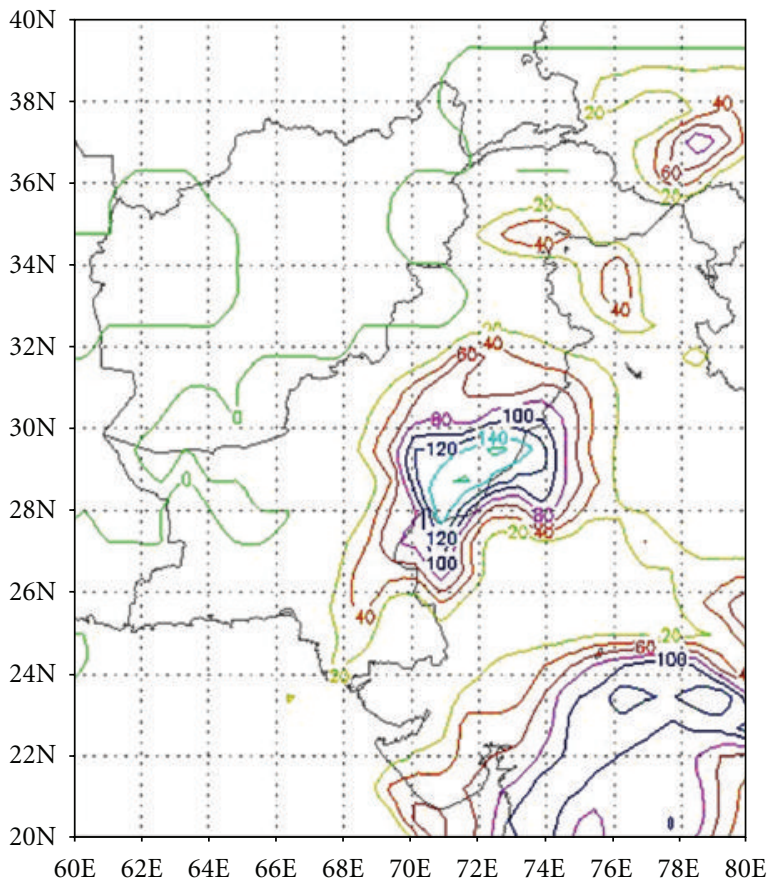

(c)

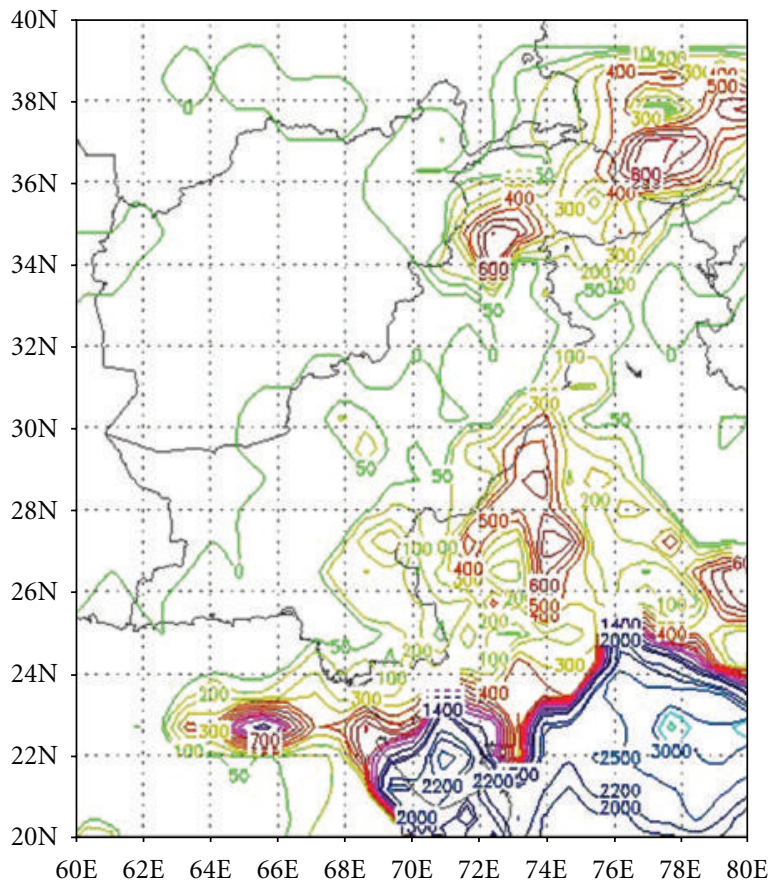

(b)

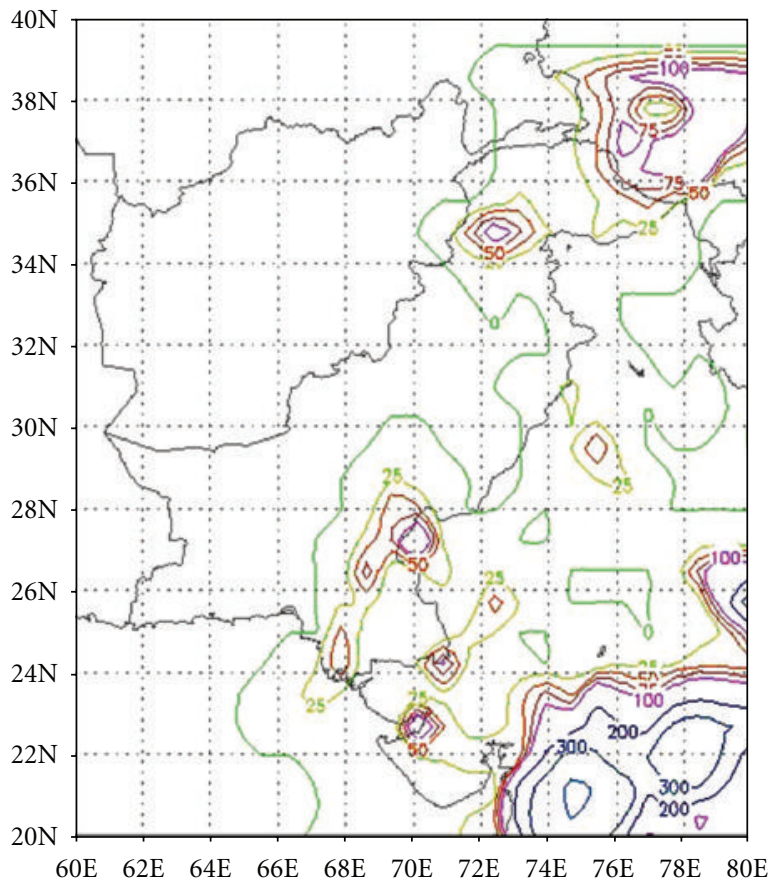

(d)

FIGURE 8: Model simulated isohyetal maps for the month of July 2001 with four parameterization schemes: Grell-AS, Grell-FC, modified Kuo and Betts-Miller schemes.

be interesting to mention here that 1998 was the starting year of a severe drought in Pakistan, which lasted up to the year 2000. Due to this drought, the agricultural productivity in the country was badly affected. On the other hand, during the year 2001, the precipitation over some parts of the country exceeded the normal and some areas in the northern parts of the country observed exceptionally high rainfall rate. July 23rd of the year 2001 witnessed heavy rainfall in a cloud burst fashion over some of the northern parts of Pakistan (Districts of Mansehra, Abbottabad, Rawalpindi, and Islamabad). This heavy precipitation exceeded the recorded maximum rainfall in Islamabad, during a single spell, and caused severe economic and life loss. In this work, we have tried to explore the capabilities of RegCM3 and the 


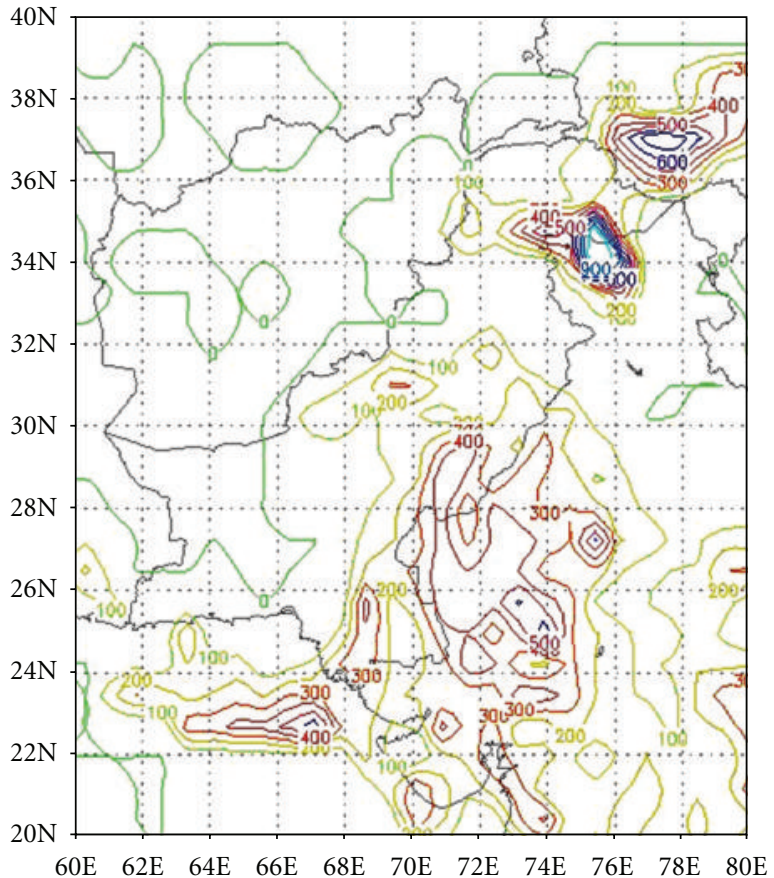

(a)

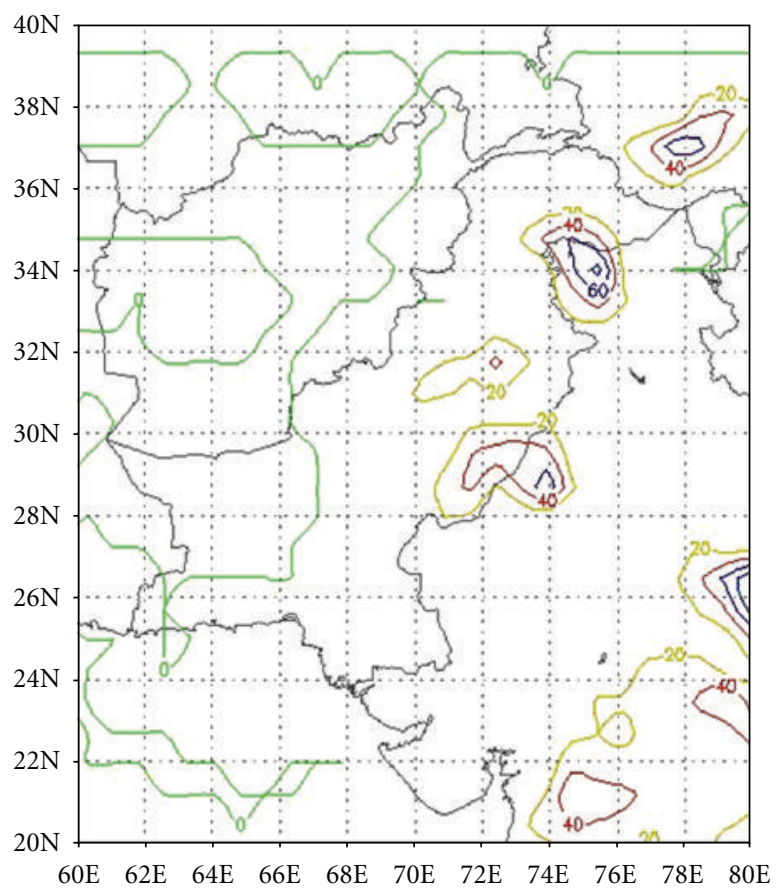

(c)

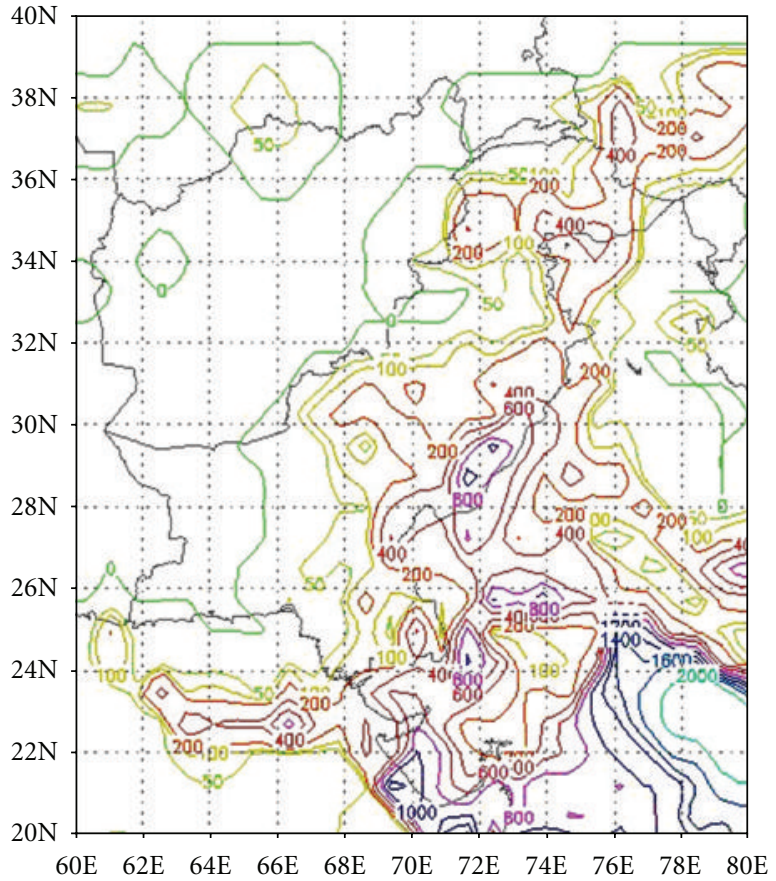

(b)

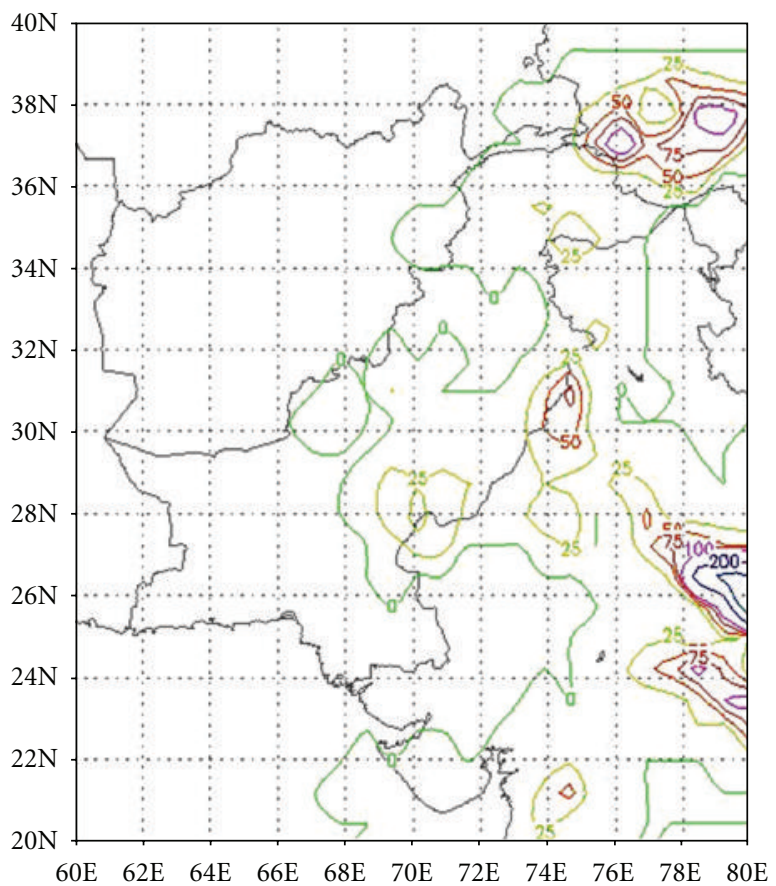

(d)

FIGURE 9: Model simulated isohyetal maps for the month of August 2001 with four parameterization schemes: Grell-AS, Grell-FC, modified Kuo and Betts-Miller schemes.

effects of the use of different convective closure schemes, on the intensity and spatial patterns of the precipitation during the summer monsoon months (July, August and September) of the selected years (1998 and 2001). The model was initialized using the NCEP reanalysis data having spatial resolution of $2.5^{\circ} \times 2.5^{\circ}$ and temporal resolution of $6 \mathrm{~h}$. The model domain was from $5 \mathrm{~N}$ to $45 \mathrm{~N}$ and $55 \mathrm{E}$ to $105 \mathrm{E}$ with a spatial resolution of $90 \mathrm{~km}$, and a 1:3 nesting was provided over a domain from $24 \mathrm{~N}$ to $36 \mathrm{~N}$ and $60 \mathrm{E}$ to $76 \mathrm{E}$ to focus on Pakistan. USGS Topographic data and US Department of Agriculture land use data of 10-minute resolution were used (see Figures 1 and 2). 


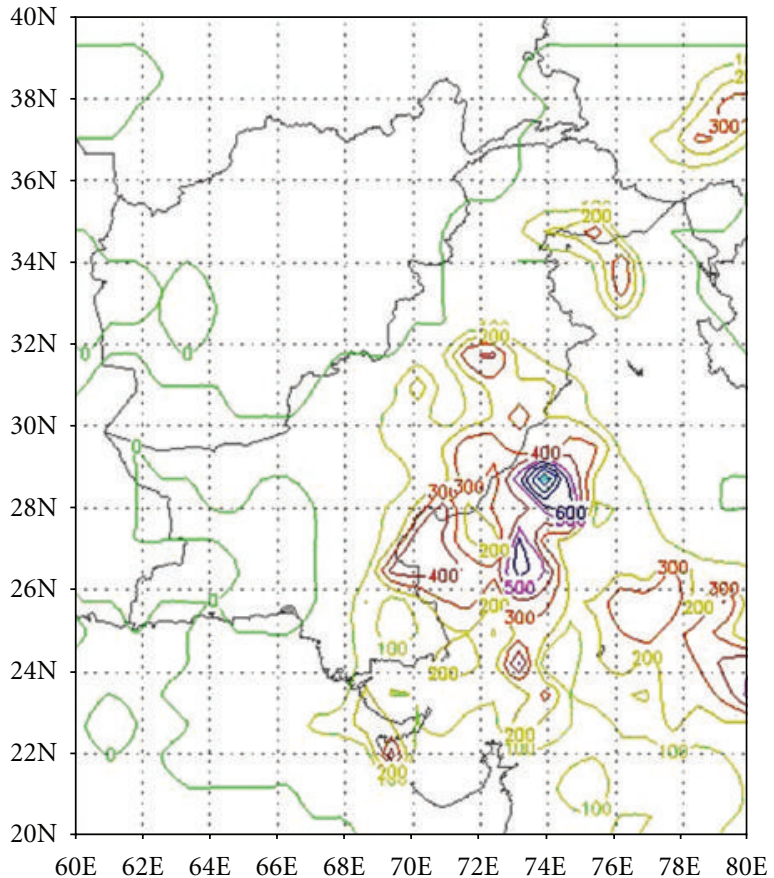

(a)

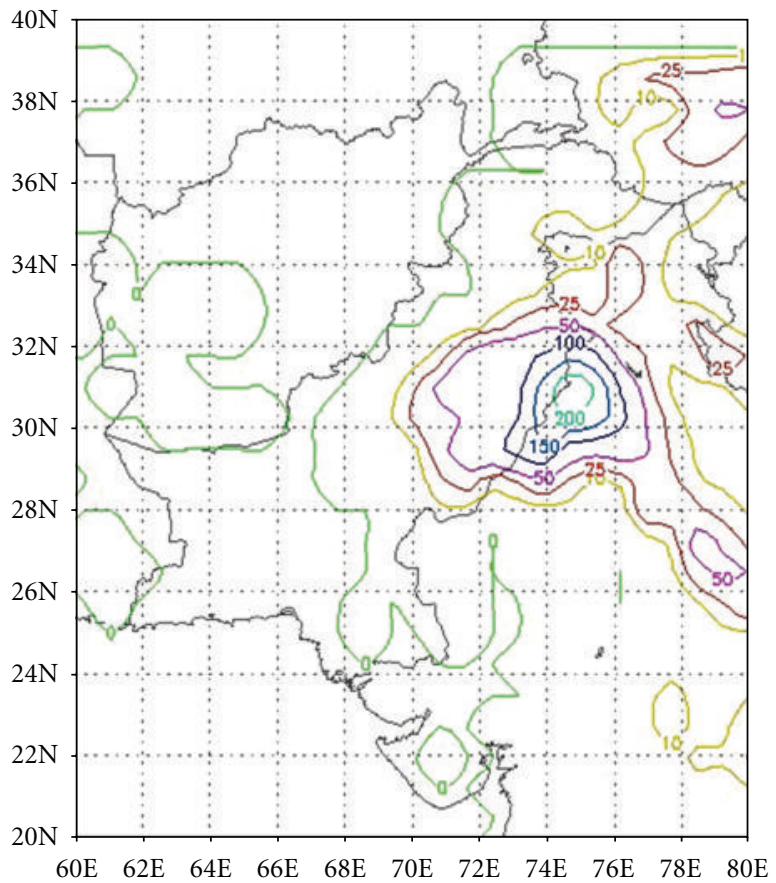

(c)

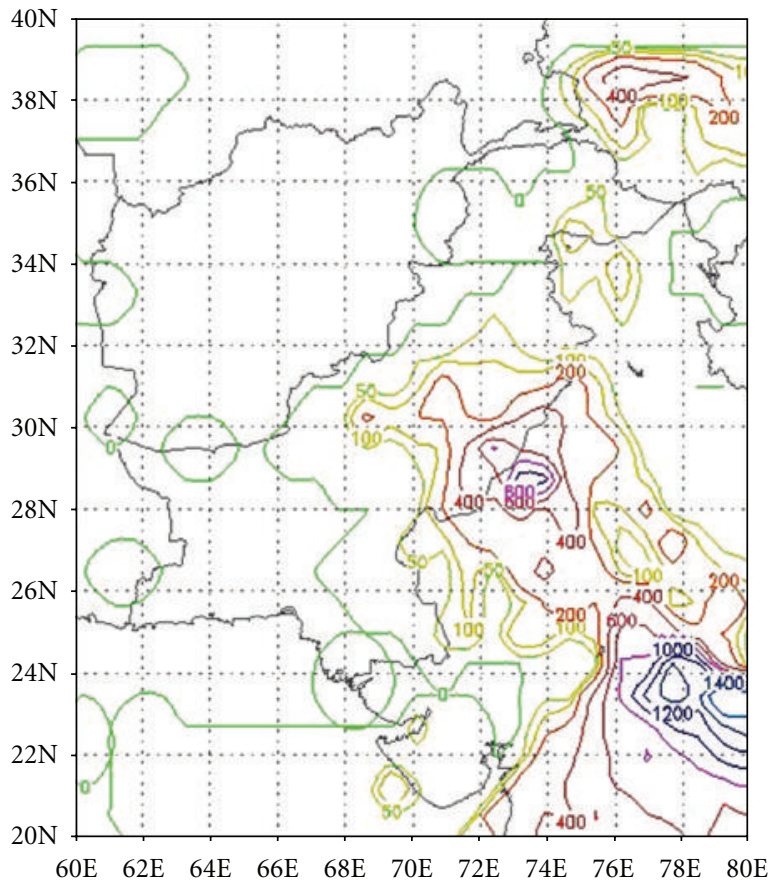

(b)

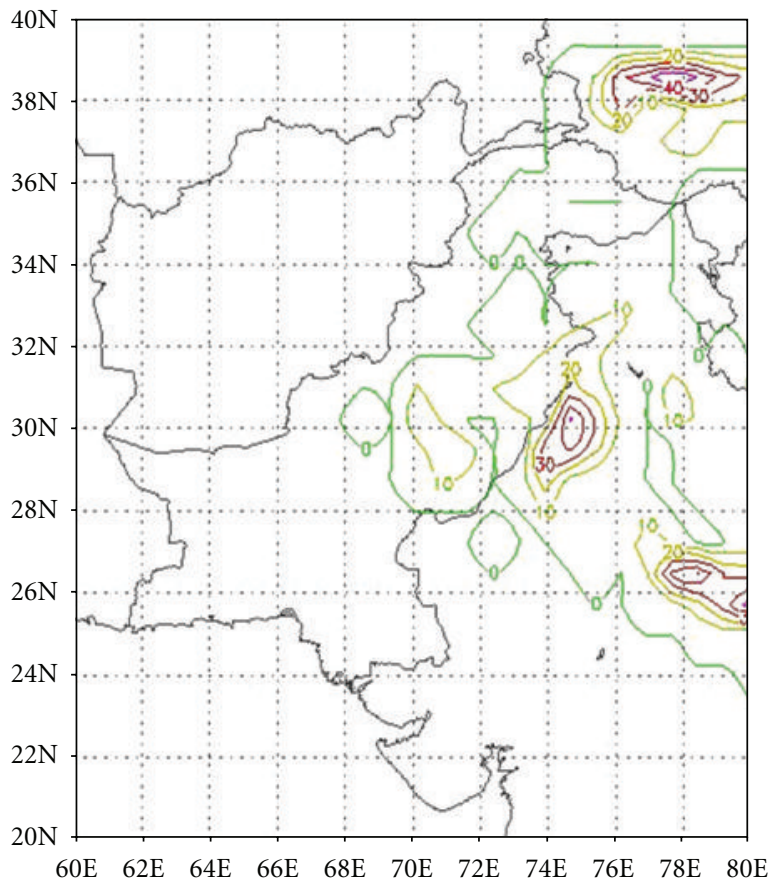

(d)

Figure 10: Model simulated isohyetal maps for the month of September 2001 with four parameterization schemes: Grell-AS, Grell-FC, modified Kuo and Betts-Miller schemes.

\section{Results and Discussion}

The model predicted patterns of the total monthly precipitation for the months of July, August and September are presented and compared with the Climate Research Unit (CRU) data and the observed monthly isohyetal maps prepared by the Pakistan Meteorological department (PMD) for the corresponding months. Figures $3(\mathrm{a})-3(\mathrm{~d})$ show the results for the month of July, 1998, using four different cumulus parameterization schemes, (i) Grell with Arakawa-Shubert closure (AS), (ii) Grell with Fritsch-Chappel closure (FC), (iii) Modified Kuo and (iv) Betts-Miller schemes respectively. Similarly Figures 4(a)-4(d) and Figures 5(a) -5 (d) show the predicted precipitation patterns for the months of August 


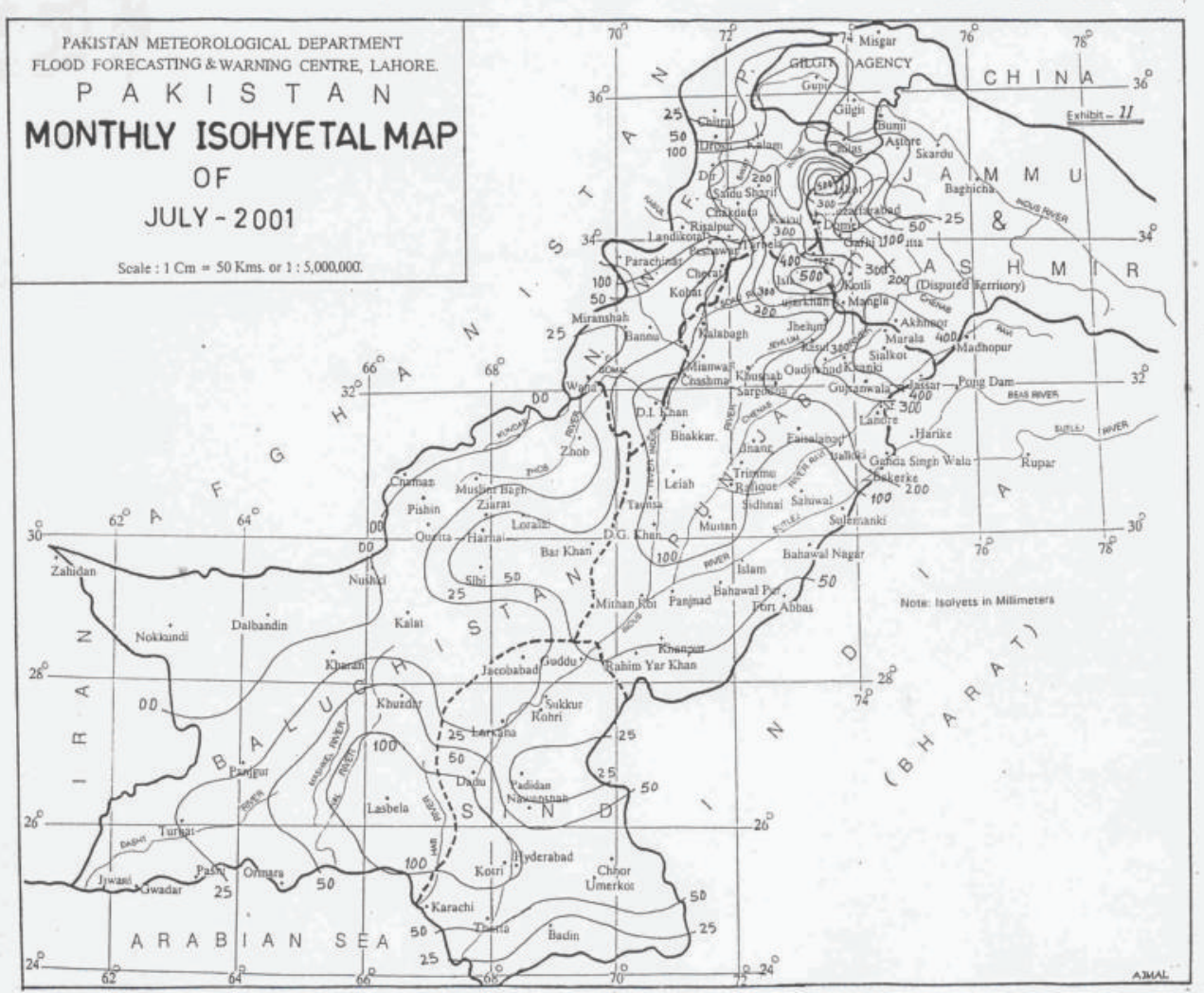

(a)

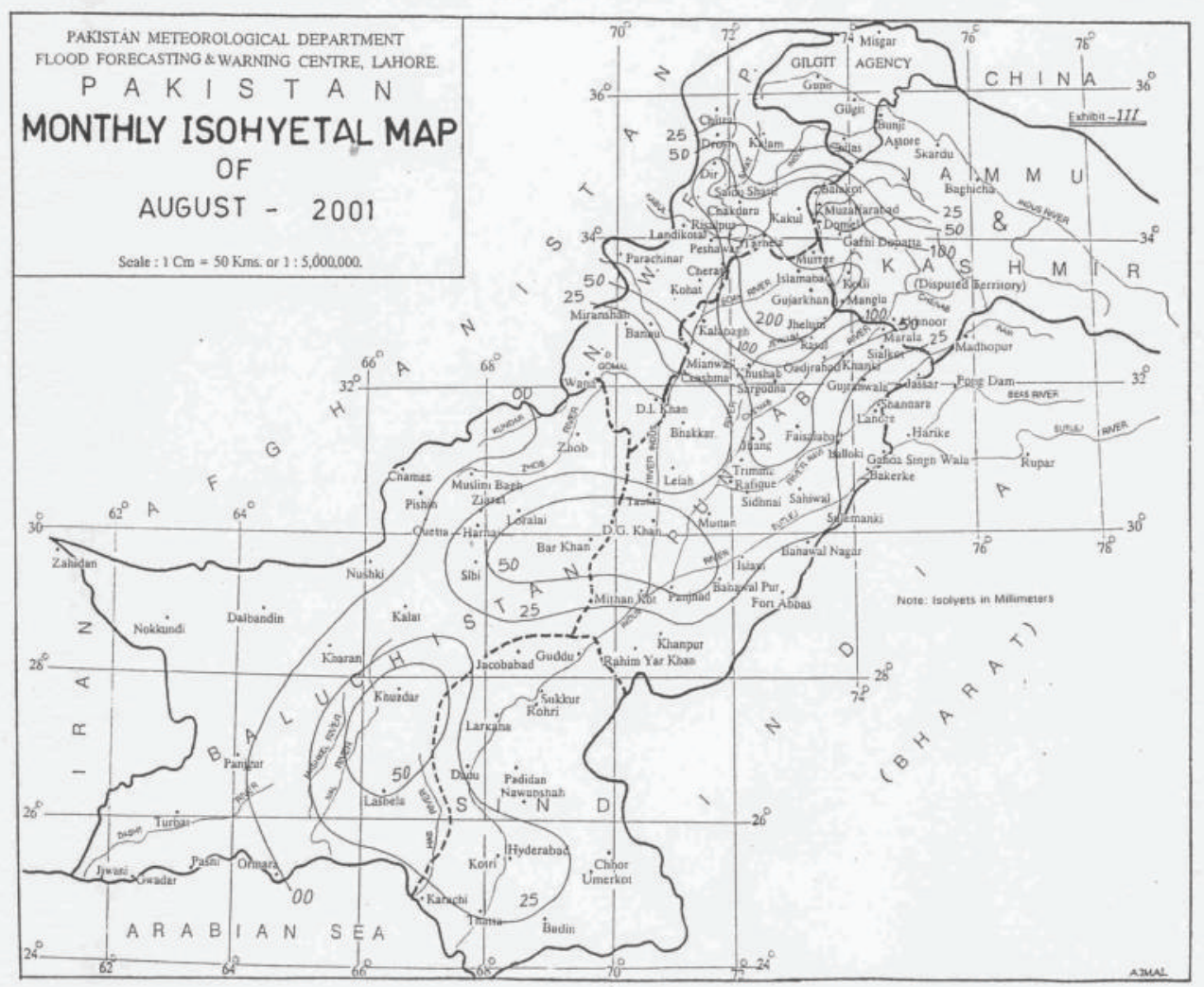

(b)

FIGURe 11: Continued. 


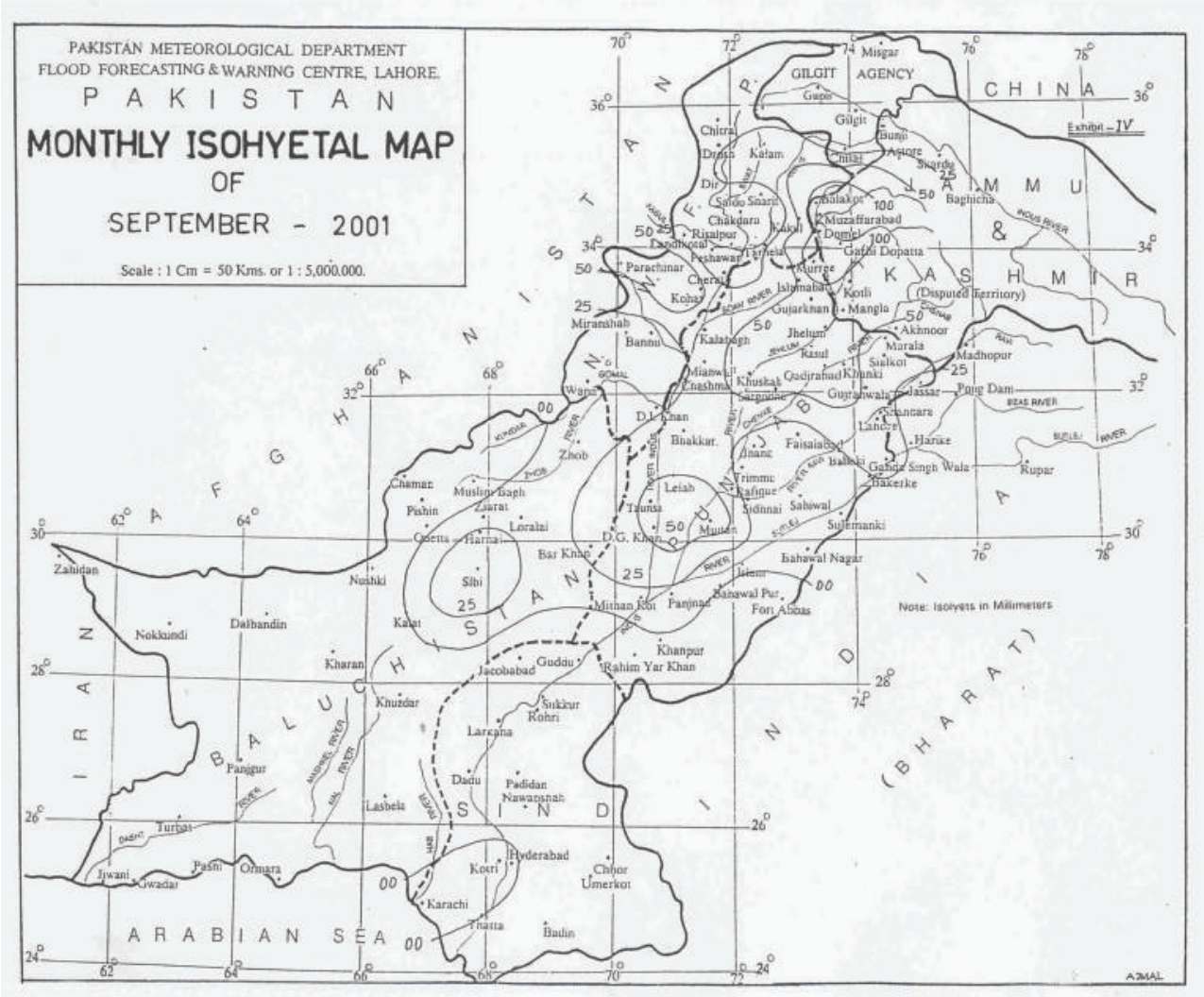

(c)

FIgURE 11: Isohyetal maps of the observed PMD data for the months of July, August, and September, 2001.

and September of 1998. Figures 6(a)-6(c) show the CRU data and Figures 7(a) and 7(b) present the PMD data for the corresponding months of the year.

Although the predicted precipitation patterns were quite different from one scheme to other, one thing could be stated readily from a close observation of the results as was also expected from the model physics that the modified Kuo and Betts-Miller schemes would underpredict the rainfall. On the other hand, predictions of Grell scheme with both AS and FC closures predicted higher precipitation when compared with the observations, especially in the south-eastern plain regions of Pakistan and the adjoining Indian areas.

Figures 8, 9 and 10 show the model simulation results for the three months of the year 2001 with the 4 convective closure schemes while Figures 11(a)-11(c) represent the PMD data for the corresponding months of the year 2001. In this case, the results are compared with the monthly isohyetal maps based on the observational data of PMD. For the month of July 2001, both closures of the Grell scheme well predicted peak rainfall centered at $34-35 \mathrm{~N}$ and $72-74 \mathrm{E}$ with contours showing $600 \mathrm{~mm}$, when compared with the PMD data. A second peak at $30 \mathrm{~N}$ and $68 \mathrm{E}$ also compared well with the observed peak location. Its intensity was predicted as $200 \mathrm{~mm}$ and $50 \mathrm{~mm}$ by the AS and FC closures respectively, whereas the observed peak was also about $50 \mathrm{~mm}$. From this, it seems that the Arakawa closure overpredicted this peak. The third small peak of $500 \mathrm{~mm}$ exactly over Islamabad has been missed by all the schemes. This was probably due to coarse spatial resolution of the model as we see an extension of first peak with a contour of $100 \mathrm{~mm}$ (AS) and $50 \mathrm{~mm}$ (FC) over a much wider area than the city of Islamabad only. A comparison of the predicted precipitation patterns for the months of August and September depicted similar results when compared with the PMD data. The other two schemes, modified Kuo and Betts-Miller (BM) not only underpredicted but also missed some of the low intensity peaks in the central and western regions of Pakistan. The Kuo scheme however seems to be better than BM as it captured the patterns although underpredicted the precipitation intensities over mountains. These schemes however did not predict that excessive precipitation over desert regions of Pakistan and India as by Grell closures. It may therefore be recommended to further improve the Kuo scheme so that it improves its prediction over mountains.

\section{Conclusions}

In this work, we have simulated the summer monsoon precipitation intensity and patterns for the months of July, August and September of the years 1998 (a dry year) and the year 2001 (a wet year) using RegCM3. The model predictions are compared with the CRU observational data and the isohyetal maps prepared by Pakistan Meteorological 
Department (PMD) based upon the data recorded at its surface synoptic observatories.

The results obtained during this work seem to be quite encouraging and it can be concluded that some of the closure schemes of RegCM3 could be used to predict summer monsoon precipitation over some specific regions of southAsia. The results of Grell parameterization scheme with both closures $[23,24]$ compared well with the observations (although on higher side) while the modified Kuo and BettsMiller schemes underpredicted the precipitation intensity, although, the later two schemes captured the precipitation patterns and location of some of the peaks. It is recommended to further test the model for prediction of monsoon precipitation over south Asia. Perhaps some improvement in the Kuo scheme would yield more suitable results than the Grell with both closures which over predicted the monsoon precipitation over south-eastern desert region of Pakistan and adjoining indian area.

\section{Acknowledgments}

R. Avila acknowledges the financial support provided by DGAPA-UNAM (research stay at the Center for Aerospace and Education, University of California, Irvine, USA). The authors are also indebted to Pakistan Meteorological Department (PMD) for providing the observed data.

\section{References}

[1] L. Gates, J. F. B. Mitchell, G. J. Goer, U. Cubasch, and V. P. Meleshko, "Climate modeling, climate prediction and model validation," in Climate Change 1992: The Supplementary Report to the IPCC Scientific Assessment, J. T. Houghton, B. A. Callander, and S. K. Varney, Eds., pp. 97-134, Cambridge University Press, Cambridge, UK, 1992.

[2] X. Gao, Z. Zhao, and F. Giorgi, "Changes of extreme events in regional climate simulations over East Asia," Advances in Atmospheric Sciences, vol. 19, no. 5, pp. 927-942, 2002.

[3] L. R. Leung, L. O. Mearns, F. Giorgi, and R. L. Wilby, "Regional climate research," Bulletin of the American Meteorological Society, vol. 84, no. 1, pp. 89-95, 2003.

[4] D. K. Lee and M. S. Suh, "Ten-year east Asian summer monsoon simulation using a regional climate model (RegCM2)," Journal of Geophysical Research D, vol. 105, no. 24, pp. 2956529577, 2000.

[5] G. J. Holland, "The maximum potential intensity of tropical cyclones," Journal of the Atmospheric Sciences, vol. 54, no. 21, pp. 2519-2541, 1995.

[6] F. Giorgi and L. O. Mearns, "Approaches to the simulation of regional climate change: a review," Reviews of Geophysics, vol. 29, no. 2, pp. 191-216, 1991 .

[7] F. Giorgi and L. O. Mearns, "Introduction to special section: regional climate modeling revisited," Journal of Geophysical Research, vol. 104, pp. 6335-6352, 1999.

[8] J. C. Petch and J. Dudhia, "The importance of the horizontal advection ofhydrometeors in a single-column model," Journal of Climate, vol. 11, no. 9, pp. 2437-2452, 1998.

[9] F. Giorgi, M. R. Marinucci, and G. T. Bates, "Development of a second-generation regional climate model (RegCM2). Part I: boundary-layer and radiative transfer processes," Monthly Weather Review, vol. 121, no. 10, pp. 2794-2813, 1993.
[10] F. Giorgi, M. R. Marinucci, and G. T. Bates, "Development of a second-generation regional climate model (RegCM2). Part I: boundary-layer and radiative transfer processes," Monthly Weather Review, vol. 121, no. 10, pp. 2814-2832, 1993.

[11] F. Giorgi, M. R. Marinucci, G. T. Bates, and G. De Canio, "Development of a second-generation regional climate model (RegCM2). Part II: convective processes and assimilation of lateral boundary conditions," Monthly Weather Review, vol. 121, no. 10, pp. 2814-2832, 1993.

[12] M. P. Dudek, X. Z. Liang, and W. C. Wang, "A regional climate model study of the scale dependence of cloud-radiation interactions," Journal of Climate, vol. 9, no. 6, pp. 1221-1234, 1996.

[13] W. C. Wang, S. Wong, J. K. Sundet, and I. S. R. Isaksen, "Atmospheric ozone as a climate gas: coupled climatechemistry model study," in Proceedings of the Quadrennial Ozone Symposium, vol. 63-64, p. 760, Hokkaido University, Sapporo, Japan, July 2000.

[14] J. T. Houghton, B. A. Callander, and S. K. Varney, Climate Change 1992: The Supplementary Report to the IPCC Scientific Assessment, Cambridge University Press, Cambridge, UK, 1992.

[15] R. E. Dickinson, R. M. Errico, F. Giorgi, and G. T. Bates, "A regional climate model for the western United States," Climatic Change, vol. 15, no. 3, pp. 383-422, 1989.

[16] F. Giorgi, "Simulation of regional climate using a limited area model nested in a general circulation model," Journal of Climate, vol. 3, pp. 941-963, 1990.

[17] F. Giorgi and G. T. Bates, "The climatological skill of a regional model over complex terrain," Monthly Weather Review, vol. 117, no. 11, pp. 2325-2347, 1989.

[18] R. E. Dickinson, A. Henderson-Sellers, and P. J. Kennedy, "Biosphere-atmosphere transfer scheme (BATS) version Ie as coupled to the NCAR Community Climate Model," NCAR Tech.Note NCAR/TN-387+STR, National Center for Atmospheric Research, Boulder, Colo, USA, 1993.

[19] R. A. Anthes, "A cumulus parameterization scheme utilizing a one-dimensional cloud model," Monthly Weather Review, vol. 105, no. 3, pp. 270-286, 1977.

[20] E. Y. Hsie, R. A. Anthes, and D. Keyser, "Numerical simulation of frontogenesis in a moist atmosphere," Journal of the Atmospheric Sciences, vol. 41, no. 17, pp. 2581-2594, 1984.

[21] A. A. M. Holtslag, E. I. F. De Bruijn, and H. L. Pan, "A high resolution air mass transformation model for short-range weather forecasting," Monthly Weather Review, vol. 118, no. 8, pp. 1561-1575, 1990.

[22] G. A. Grell, "Prognostic evaluation of assumptions used by cumulus parameterizations," Monthly Weather Review, vol. 121, no. 3, pp. 764-787, 1993.

[23] A. Arakawa and W. H. Schubert, "Interaction of a cumulus cloud ensemble with the large-scale environment, Part I," Journal of the Atmospheric Sciences, vol. 31, pp. 674-701, 1974.

[24] J. M. Fritsch and C. F. Chappell, "Numerical prediction of convectively driven mesoscale pressure systems. Part I: convective parameterization," Journal of the Atmospheric Sciences, vol. 37, no. 8, pp. 1722-1733, 1980.

[25] A. K. Betts, "A new convective adjustment scheme. Part I: observational and theoretical basis," Quarterly Journal, vol. 112, no. 473, pp. 677-691, 1986.

[26] A. K. Betts and M. J. Miller, "A new convective adjustment scheme. Part II: single column tests using GATE wave, BOMEX, ATEX and arctic air-mass data sets," Quarterly Journal, vol. 112, no. 473, pp. 693-709, 1986.

[27] X. Zeng, M. Zhao, and R. E. Dickinson, "Intercomparison of bulk aerodynamic algorithms for the computation of sea 
surface fluxes using TOGA COARE and TAO data," Journal of Climate, vol. 11, no. 10, pp. 2628-2644, 1998.

[28] J. S. Pal, E. E. Small, and E. A. B. Eltahir, "Simulation of regional-scale water and energy budgets: representation of subgrid cloud and precipitation processes within RegCM," Journal of Geophysical Research D, vol. 105, no. 24, pp. 2957929594, 2000.

[29] X. Z. Liang, K. E. Kunkel, and A. N. Samel, "Development of a regional climate model for U.S. Midwest applications. Part I: sensitivity to buffer zone treatment," Journal of Climate, vol. 14, no. 23, pp. 4363-4378, 2001.

[30] A. J. Heymsfield and L. J. Donner, "A scheme for parameterizing ice-cloud water content in general circulation models," Journal of the Atmospheric Sciences, vol. 47, no. 15, pp. 18651877, 1990.

[31] H. W. Detering and D. Etling, "Application of the E- $\varepsilon$ turbulence model to the atmospheric boundary layer," BoundaryLayer Meteorology, vol. 33, no. 2, pp. 113-133, 1985.

[32] C. W. Fairall, E. F. Bradley, D. P. Rogers, J. B. Edson, and G. S. Young, "Bulk parameterization of air-sea fluxes for tropical ocean global atmosphere coupled-ocean atmosphere response experiment," Journal of Geophysical Research C, vol. 110 C, no. 2, pp. 3747-3764, 1996.

[33] J. Polcher, K. Laval, L. Dümenil, J. Lean, and P. R. Rowntree, "Comparing three land surface schemes used in general circulation models," Journal of Hydrology, vol. 180, no. 1-4, pp. 373-394, 1996. 

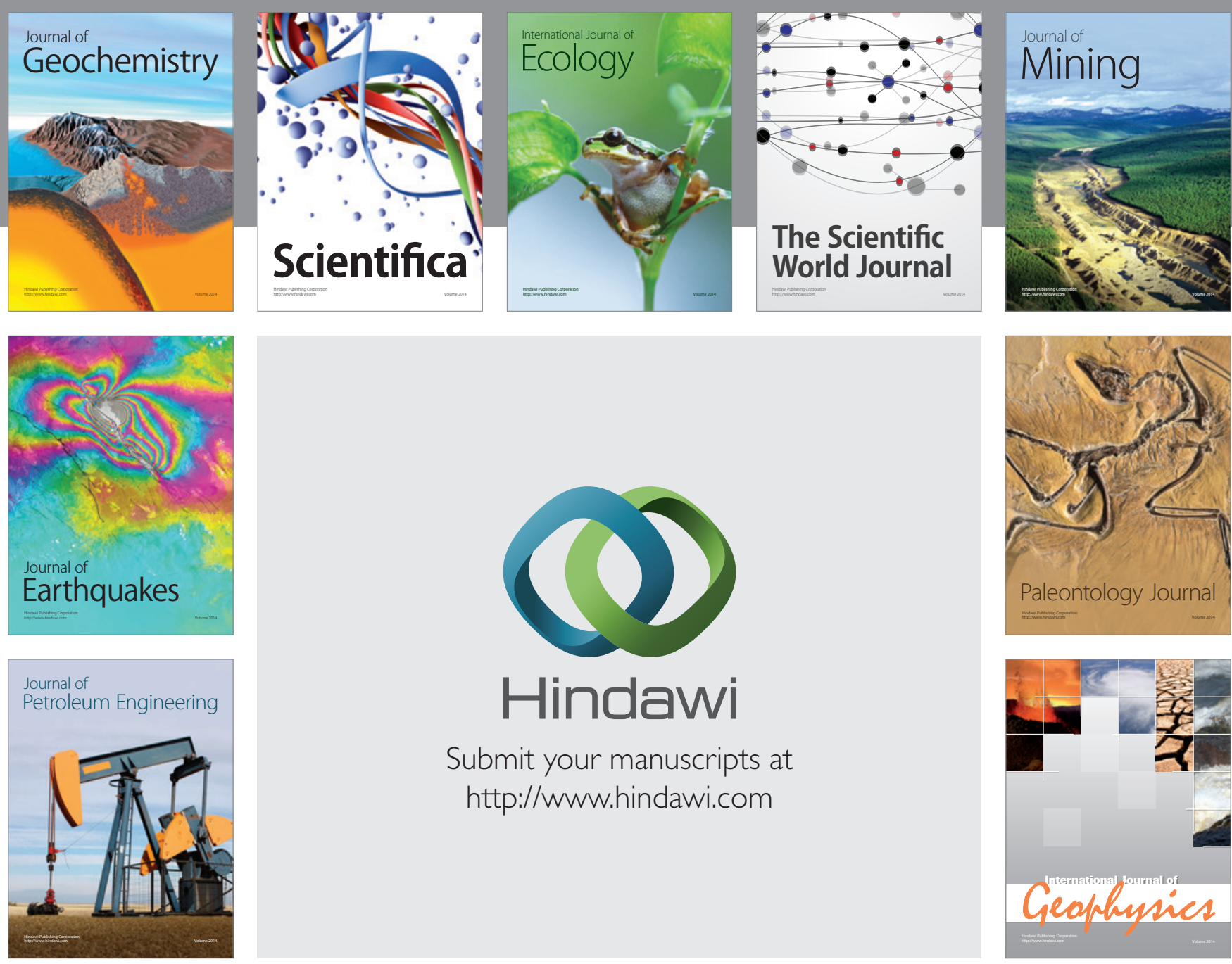

Submit your manuscripts at

http://www.hindawi.com
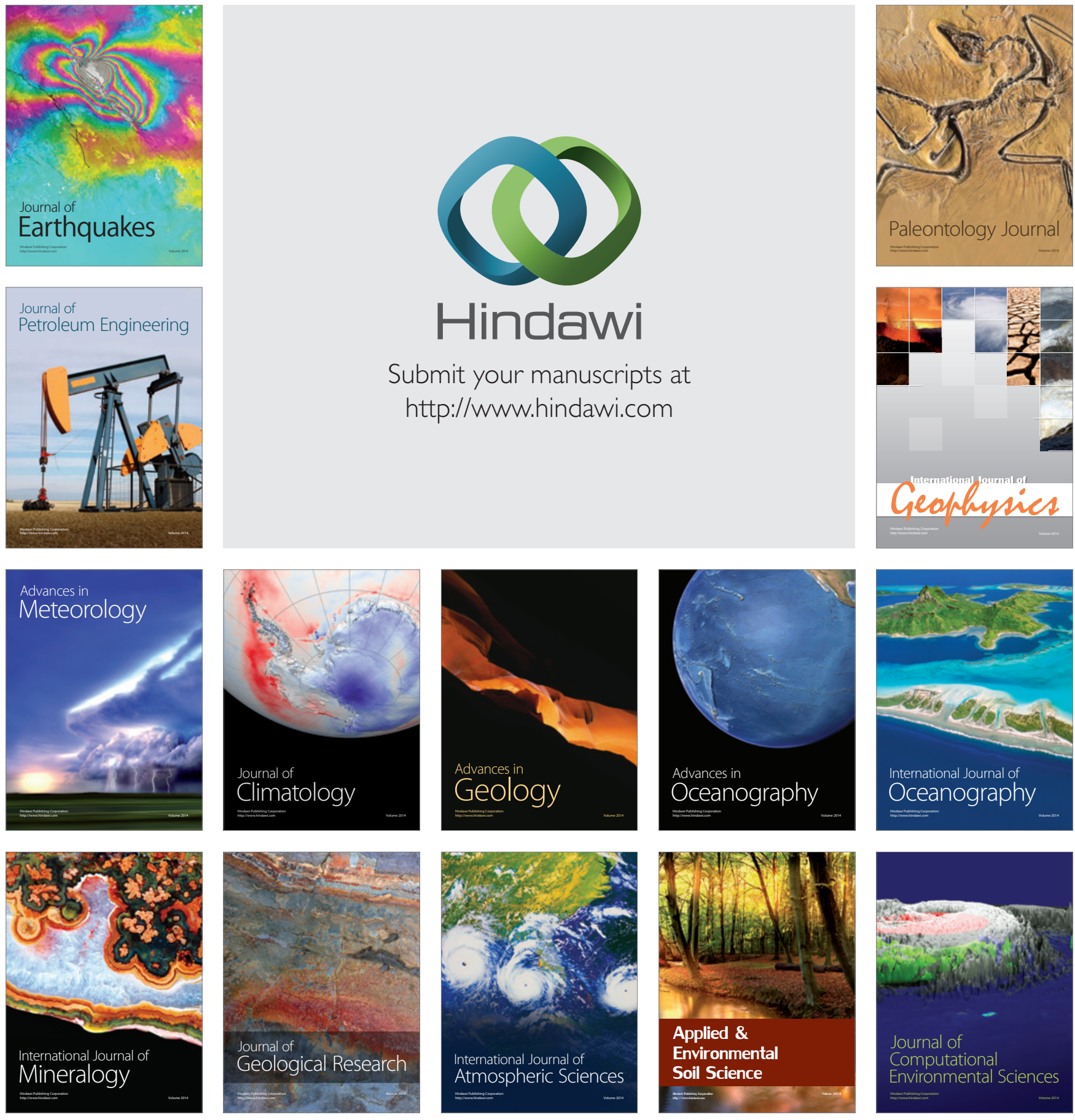